NBER WORKING PAPER SERIES

\title{
CUMULATIVE IMPACTS OF CONDITIONAL CASH TRANSFER PROGRAMS: EXPERIMENTAL EVIDENCE FROM INDONESIA
}

\author{
Nur Cahyadi \\ Rema Hanna \\ Benjamin A. Olken \\ Rizal Adi Prima \\ Elan Satriawan \\ Ekki Syamsulhakim \\ Working Paper 24670 \\ http://www.nber.org/papers/w24670
NATIONAL BUREAU OF ECONOMIC RESEARCH
1050 Massachusetts Avenue
Cambridge, MA 02138 \\ May 2018
}

We thank Aaron Berman for research assistance and Harsa Kunthara for help in the early stages of data analysis. We also thank Chris Blattman and David McKenzie for helpful comments and suggestions. Financial assistance for this project came from PNPM Support Facility (PSF), Poverty Reduction Support Facility (PRSF), and Mahkota, all supported by the Australian Department of Foreign Affairs and Trade. The views expressed herein are those of the authors and do not necessarily reflect the views of the National Bureau of Economic Research.

At least one co-author has disclosed a financial relationship of potential relevance for this research. Further information is available online at http://www.nber.org/papers/w24670.ack

NBER working papers are circulated for discussion and comment purposes. They have not been peer-reviewed or been subject to the review by the NBER Board of Directors that accompanies official NBER publications.

(C) 2018 by Nur Cahyadi, Rema Hanna, Benjamin A. Olken, Rizal Adi Prima, Elan Satriawan, and Ekki Syamsulhakim. All rights reserved. Short sections of text, not to exceed two paragraphs, may be quoted without explicit permission provided that full credit, including $\odot$ notice, is given to the source. 
Cumulative Impacts of Conditional Cash Transfer Programs: Experimental Evidence from Indonesia

Nur Cahyadi, Rema Hanna, Benjamin A. Olken, Rizal Adi Prima, Elan Satriawan, and Ekki Syamsulhakim

NBER Working Paper No. 24670

May 2018

JEL No. I38,O10

\section{ABSTRACT}

Conditional cash transfer (CCT) programs have spread worldwide, and are designed to promote comprehensive human capital investments in children, starting from encouraging pre-natal and maternal care and early childhood health interventions and continuing through incentivizing school attendance. Yet evaluating these claims over more than a few years is hard, as most CCT experiments extend the program to the control group after a short experimental period. This paper experimentally estimates the impacts of Indonesia's cash transfer program (PKH) six years after the program launched, using data from about 14,000 households in 360 sub-districts across Indonesia, taking advantage of the fact that treatment and control locations remained largely intact throughout the period. We find that PKH continues to have large static incentive effects on many of the targeted indicators, increasing usage of trained health professionals for childbirth dramatically and halving the share of children age 7-15 who are not enrolled in school. Wage labor for 13-15 year olds was reduced by at least one-third. We also begin to observe impacts on outcomes that may require cumulative investments: for example, six years later, we observe large reductions in stunting and some evidence of increased high school completion rates. The results suggest that CCT investments can have substantial effects on the accumulation of human capital, and that these effects can persist even when programs are operating at large-scale without researcher intervention.

Nur Cahyadi

National Team for Acceleration of

Poverty Reduction (TNP2K)

Grand Kebon Sirih Building, 4th floor

J1 Kebon Sirih no 35

Jakarta 10110, INDONESIA

nur.cahyadi@tnp2k.go.id

Rema Hanna

Kennedy School of Government

Harvard University

79 JFK Street

Cambridge, MA 02138

and NBER

Rema_Hanna@hks.harvard.edu

Benjamin A. Olken

Department of Economics, E52-542

MIT

77 Massachusetts Avenue

Cambridge, MA 02139

and NBER

bolken@mit.edu
Rizal Adi Prima

Royal Melbourne Institute of Technology

School of Economics, Finance and Marketing

445 Swanston $\mathrm{St}$

Melbourne VIC 3000 Australia

rizal.prima@rmit.edu.au

Elan Satriawan

National Team for Acceleration of

Poverty Reduction (TNP2K)

Grand Kebon Sirih Building, 4th floor,

Jl Kebon Sirih no 35

Jakarta 10110, INDONESIA

and Universitas Gadjah Mada

esatriawan@ugm.ac.id

Ekki Syamsulhakim

National Team for Acceleration of

Poverty Reduction (TNP2K)

Grand Kebon Sirih Building, 4th floor,

J1 Kebon Sirih no 35

Jakarta 10110, INDONESIA

and Universitas Padjadjaran

ekki.syamsulhakim@fe.unpad.ac.id 


\section{INTRODUCTION}

Perhaps the most remarkable innovation in welfare programs in developing countries over the past few decades has been the invention and spread of conditional cash transfer programs (CCTs). These programs provide regular cash transfers to poor households, but condition the transfers on households making a series of human capital investments in their young children. These conditions typically begin before birth - prenatal care and deliveries by trained midwives or doctors are usually conditions - and continue through early childhood health investments (immunizations, growth monitoring) and enrollment in primary and junior secondary school. These programs began in the 1990s in Mexico, Bangladesh and Brazil, and today over 63 countries have at least one CCT program (Bastagli et al. 2016), covering millions of families worldwide (Robles, Rubio, and Stampini 2015; World Bank 2018).

The theory behind these conditions - and the reason they start before birth and continue throughout childhood - is that static investments in human capital at every stage of the life cycle will accumulate as children grow up, and the cumulative investments in human capital will eventually lead to substantial improvements in child outcomes that may affect inter-generational poverty. For example, Santiago Levy, who helped create the CCT model with the Mexican PROGRESA program in the 1990s, argued, "clearly achieving good health is a cumulative process, and temporary investments in nutrition are of little help. The same is true of education: children must be supported year after year.... [PROGRESA's] central effects will gradually occur through the accumulation of human capital” (Levy 2006).

Given the worldwide scope of CCT programs, there has been substantial interest in understanding whether the static CCT conditions indeed lead to cumulative improvements in child outcomes. This question, however, has encountered an empirical challenge. Many CCTs, starting with PROGRESA, began with randomized controlled trials on a pilot basis prior to scale-up, and the vast majority of the evidence on the impact of CCTs comes from these trials (for example, see Behrman and Todd, 1999; Gertler, 2004). However, to our knowledge, virtually all of these programs extended the CCT to the control group after a 
relatively short pilot period - 18 months in the PROGRESA case, for example. ${ }^{1}$ While this phase-in experimental design is useful for studying the short-run, static impacts of the CCT on the health and education behaviors they incentivize, the fact that the control group is ultimately treated makes it much harder to credibly estimate cumulative effects from sustained exposure to the programs as children grow up having been exposed to the program over a sustained period of time. ${ }^{2}$

A second, related question is whether the programs themselves continue to be effective - even in the static sense of continuing to increase compliance with incentivized behaviors on new children entering the program, or those who were quite young when the program began and have now aged into the conditions for older children. There are a number of reasons to expect that the "static" effects of the program may change over time. Some have argued that, in many cases, interventions are less effective when implemented by the government at scale than in a smaller pilot stage, when researchers are more likely to be paying attention to the implementation (see, for example, Bold et al. 2015; and the related discussions in Banerjee et al. 2017 and Muralidharan and Niehaus 2017). Moreover, even if the program did have an initial effect on compliance with the incentivized behaviors, the treatment effects could weaken after it became more commonplace and people's initial excitement of being in the program faded, or once people learned that the conditions placed on health and education behaviors were not always perfectly enforced by the government. Furthermore, natural improvements over time in socioeconomic conditions, coupled with no changes in the nominal level of benefit payments, could render these cash payments less relevant to households' decisions. Since most CCT experiments extend the program to the control group after a short

\footnotetext{
1 To our knowledge, there are two notable exceptions. First, Barrera-Osorio, Linden, and Saavedra (2017), experimentally evaluate the long-run effect (8-12 years) of an unusual CCT and savings program in Bogotá, Colombia with an intact control group that focused on incentivizing high-school enrollment, and studied the effect on tertiary enrollment in universities. Second, Kandpal et al. (2016) study the effect of the Philippines's Pantawid program 31 months (or, 2.6 years) after the program launch.

${ }^{2}$ Some papers exploit the fact that there is a time gap between treatment and control (even if for a short period) and this may have effects on different cohorts of children due to differences in exposure effects, and thus look at mediumor long-run effects for children affected by the program (for example, see Behrman, Parker, and Todd 2011; Barham, Macours, and Maluccio 2017; Kugler and Rojas 2018). While this is very informative in terms of outcomes, it could result in underestimates of the impacts as the control group is also exposed to the program, just a few years later. Others exploit non-experimental variation using discontinuities in who received the transfers (e.g. Filmer and Schady 2014) or cohort analysis across areas with higher and lower program intensity (Parker and Vogl 2017) to measure the longer-run results.
} 
time, understanding whether the programs continue to be effective even in a static sense after a short experimental initial period is also challenging. ${ }^{3}$

This study aims to answer these questions using an unusual, large-scale policy experiment in Indonesia. We study Indonesia's conditional cash transfer program, Program Keluarga Harapan or PKH. Starting in early 2008, the government introduced PKH in 438 sub-districts across Indonesia (randomly selected from 736, spread out over 50 districts), to a total of about 700,000 households. Targeted households received between 600,000 to 2,200,000 Rupiah (approximately USD 60 to 220) per year, with typical CCT conditions for children (pre- and post-natal care, deliveries with trained birth attendants, regular growth monitoring, immunizations, enrollment and attendance of children in primary and junior secondary school). The World Bank conducted a follow-up survey in 2009, about two years after the roll-out, in 360 of these sub-districts, which was intended to be the end of the evaluation period (Alatas 2011).

Crucially, while PKH has subsequently been expanded to many more areas in Indonesia - by 2013 it had reached over 3,400 sub-districts, spread over 336 districts in all of Indonesia’s provinces, and covered over 2.3 million households - 60 percent of the initial control sub-districts were still not treated nearly six years later. The reason for this expansion to new provinces and districts, rather than to the control group, was that the Indonesian government chose to prioritize the expansion of the program to new areas such that the program would be spread throughout the country rather than focused intensely in a small number of geographic areas.

For research, however, this presents a unique opportunity because the initial randomization of subdistricts to treatment and control status continues to induce random variation in program placement six years later. To study the impact of the program over this longer time horizon, in 2013 we re-surveyed households that were in the initial experiment to measure medium-run outcomes. Notably, we found 95

\footnotetext{
${ }^{3}$ In fact, Molina-Millan, Barham, Macours, Maluccio, Stampini (2016) review the state of the evidence on long-run conditional cash transfers in Latin American, concluding that the mixed results imply the need for more systematic rigorous evidence.
} 
percent of the original 14,326 households in the baseline survey. ${ }^{4}$ We show that the experimental first stage - the regression of whether a household is receiving PKH on whether the household's sub-district was randomized in 2007 to be in the treatment group - is strong (F-statistic over 400), and virtually identical in magnitude six years after the program started compared to after just two years. This unique setup - where the experiment continued to run at scale for over six years without any researcher intervention in program implementation - allows us to examine whether the static effects of the program on targeted indicators persist even as the program continues over time, as well as whether these human capital investments began to accumulate over time as children grew up exposed to the program.

We start by examining the effect of the program on health-seeking behaviors. For each outcome, we present the results from our six-year follow-up. We also present corresponding results from the twoyear follow-up survey carried out by the World Bank, which we re-analyzed using exactly the same IV regression specifications that we use in this paper, in order to compare results over time holding the specification constant.

We find that the conditional cash transfer program continued to have a substantial impact on increased utilization of a number of health services, even after six years. For example, treated households were more likely to have childbirth assisted by a skilled birth attendant (doctor or midwife; increased by 16 to 23 percentage points, depending on specification) and delivery at facility for those who had given birth (increased by 13 to 17 percentage points). These are dramatic increases - they imply that the PKH program reduced the share of children born without the aid of a skilled birth attendant by 69 - 100 percent. Pre- and post-natal visits, as well as growth monitoring visits for children, increased at two years, but we can no longer distinguish this effect from zero after six years; this may because the control group also increased their overall number of visits in the intervening years and "caught up." Conversely, while there was no

\footnotetext{
${ }^{4}$ The 95 percent follow up rate includes finding at least one household member. However, as we discuss in more depth below, not all household members could be found in the same household (or somewhere else within the subdistrict). We found and interviewed 78 percent of all children who were aged 6-15 in the baseline survey; there is no differential attrition nor any substantial differences in reason for migration (i.e., for work, to follow spouse, or for school) between the treatment and control groups.
} 
observable impact on immunizations in the short-run, we find that immunization rates increased by the sixyear follow-up—in fact, we observe a 8 to 10 percentage point - 15 to 19 percent - increase in the share of children who have received the 'complete' set of immunizations for their age (where complete is defined by the Indonesian Ministry of Health guidelines.). On net, many health-seeking behaviors continued to be substantially increased by the PKH program at the six-year mark, despite overall secular improvements in health seeking behaviors throughout our sample area.

Turning to actual health outcomes for young children, which may reflect cumulative health investments over multiple years, we find very large impacts on children's propensity to be stunted or severely stunted in the six-year follow-up. In fact, we observe a 23 to 27 percent reduction in the probability of being stunted (defined as being 2 standard deviations less than the WHO's height-for-age standard), and a 56 to 62 percent reduction in the probability of being severely stunted ( 3 standard deviations less than the WHO's height-for-age standard). There were no detectable stunting effects in the two-year follow-up, which suggests that cumulative health investments over several years may be important. We find no impact on malnourishment (low weight-for-age); weight-based measures respond more quickly to nutrition and health status, whereas stunting is thought to respond to early childhood conditions over a period of several years (UNICEF 2013; Hoddinott et al. 2013). We do not observe any effects on parent-reported measures of acute illness of children under 5, such as diarrhea, fever, or coughs in the last month.

We then turn to investigate education outcomes. We begin by examining outcomes for the younger age cohorts, for whom the program explicitly seeks to incentivize enrollment and attendance. Overall, school enrollment rates for the targeted age group - 7-15 year olds - are about 4 percentage points higher for the treatment than for the control group in the six-year follow-up. Since 92.4 percent of children of this age in the control group sample are already enrolled in school, this means that the program eliminated 53 percent of non-enrollment. This is slightly less than in the two-year follow-up, where the program increased enrollment by 6 to 7 percentage points, eliminating 66 to 70 percent of non-enrollment, but still shows that the program was able to halve the percentage of children who were not in school. 
To capture the cumulative effects of educational investments, we look at impacts on older children - aged 15-21 at the time of our surveys, who were in the target age range (aged 9-15) at the time PKH began. We find evidence that children aged 15-17 were about 10 percentage points more likely to still be enrolled in school. We also find some evidence that high school completion rates increased - by between 4 and 7 percentage points, representing a 16 to 29 percent increase. We find no evidence that this translated to a higher likelihood of wage employment for those aged 18 to 21 years, however, nor do we find impacts on early marriage. ${ }^{5}$

Lastly, we look at household consumption and assets to explore the program's effects on the households' current condition. Gertler, Martinez, and Rubio-Codina (2012) find that PROGRESA households invested a fraction of accumulated transfers in productive assets, which could affect the overall poverty status of the household. However, we find no evidence of this here. While the point estimates of the impact on consumption are positive, we cannot distinguish the measured impacts from zero; we also cannot reject effects equal to the size of the transfer, which was about 7 percent of household consumption. What we can rule out, however, are transformational impacts on household consumption: given our confidence intervals, we can reject that household per-capita consumption increased by more than about 10 percent. We also find no observable effect on productive household assets, such as livestock owned, or on fixed assets, such as land.

In short, PKH continued to have impacts on the incentivized health and educational investments of households six years after program introduction: in particular, it continued to impact primary and secondary school education attainment and deliveries in a facility by trained birth attendants. This occurred despite the fact that the level of benefits fell from 14 to 7 percent of monthly household consumption. This also occurred after initial researcher involvement was over, and the program was run by the government with business-as-usual practices. Perhaps more importantly, with the continued investment in children over time,

\footnotetext{
${ }^{5}$ Note that unlike the results on stunting, where children were on PKH most of their lives, the children in the 15-21 age category were older to begin with when PKH started. If we believe the cumulative effects come from PKH's focus on early childhood, these children are less likely to be impacted than the younger children.
} 
we now begin to see some substantial results on “cumulative outcomes.” In particular, stunting was greatly reduced, suggesting large health gains. Moreover, for high school-age children, school enrollment and completion increased. On the other hand, we see no transformational effects over six years of repeated cash transfers on the incomes of the beneficiaries themselves. Combined, this suggests that if conditional cash transfers are going to indeed break the cycle of poverty, this effect is going to happen through impacts on the subsequent generation, rather than through impacts on households themselves.

The rest of the paper proceeds as follows. We describe the setting, experimental design, and data in Section II. We provide the findings in Section III, while Section IV concludes.

\section{SETTING, EXPERIMENTAL DESIGN, AND DATA}

\section{A. Program}

In this paper, we study the cumulative (six-year) effects of Indonesia’s conditional cash transfer program, Program Keluarga Harapan (PKH or "Hopeful Family Program”). Launched in 2007, the program provides quarterly cash transfers to very poor households with children or pregnant and/or lactating women, with a fraction of the payment conditional on fulfilling a number of health- and education-related obligations. The goal of the program was two-fold: “(a) to reduce current poverty and (b) to improve the quality of human resources among poor households” (Alatas 2011).

Extremely poor households (Rumah Tangga Sangat Miskin) were targeted under the program. To determine their eligibility, Statistics Indonesia (BPS) surveyed households that were either included in the 2005 targeted program lists or identified as part of their sweep for poor households; the survey included 29 asset and demographic questions. They applied a proxy means test formula to this survey data, and households that were below a pre-determined cutoff were deemed to be financially eligible. Out of these, Statistics Indonesia kept households that additionally met the demographic requirements: households with a pregnant and/or lactating woman, households with children aged 0-15 years, and households with children aged 16-18 years who have not yet completed 9 years of basic education. 
Eligible households began receiving quarterly cash payments through the nearest postal office. The amount of cash was designed to be about 15 to 20 percent of annual household income, depending on the age of the children; the minimum payment per transfer was 600,000 Rupiah per household, while the maximum was 2,200,000. In order to receive the payments, households had to complete a number of conditions. For example, households with children aged 0 to 6 needed to ensure that children complete childhood immunizations and take Vitamin A capsules a minimum of twice per year, and also must take children for growth monitoring check-ups (see Appendix Figure 1 for the full list of conditions). Trained facilitators would provide the beneficiaries with information and advice, and also verify the conditions: one violation would result in a warning letter, a second violation would lead to a 10 percent cut in benefits, and a third violation would lead to program expulsion. However, in practice, the verification system did not begin until at least 2010, and even afterwards, the conditions were not always enforced.

\section{B. Sample, Experimental Design and Timing}

The Government of Indonesia piloted and tested PKH across six provinces (West Java, East Java, North Sulawesi, Gorontalo, and East Nusa Tenggara) and the capital city of Jakarta. Within each province, the government excluded the richest 20 percent of districts, and then determined which sub-districts within the remaining districts were "supply-side ready" (based on availability of midwives, doctors, and middle schools) to participate in the program. A total of 736 sub-districts were included in their sample, with 438 sub-districts randomized to the treatment group.

Out of these, 360 sub-districts were randomly chosen for data collection (180 treatment, 180 control). Appendix Figure 2 shows the distribution of sub-districts across the provinces and experimental assignments. Note that they are spread across Indonesia—specifically, on and off Java—and thus capture important heterogeneity in culture and institutions (Dearden and Ravallion 1988).

As shown in Appendix Figure 3, The World Bank conducted a baseline survey in June to August 2007, and the program was launched in these sub-districts soon afterward. The World Bank conducted a follow-up survey from October to December 2009, about two years after the start of the program; the results 
are described in Alatas (2011). We conducted a follow-up survey in September to November 2013, about six years after the intervention.

The evaluation we conduct is possible because subsequent program expansions kept the control group largely intact. Appendix Figure 4 shows the evolution of the $\mathrm{PKH}$ program over the time period that we study based on administrative data on the program's expansion. In 2009 (two-year follow-up), the program was operating in 99 percent of the locations randomized to treatment, and in 22 percent of locations randomized to control - which implied a sub-district-level 'first stage’ of 77 percentage points in 2009. By 2013 (six-year follow-up), the program had expanded somewhat, but the experiment still remained intact the program was operating in 99 percent of locations randomized to treatment, and in 39 percent of locations randomized to control, for an implied sub-district-level 'first stage' of 60 percentage points. Thus, after six years, the original sub-district-level randomization still had substantial bite. Moreover, because the program reached fewer households in areas in the control sub-districts that received the expansion between 2009 and 2013, the first stage for receiving PKH at the household level is virtually identical in both 2009 and 2013. As described below, we use the original randomization as an instrument for treatment.

\section{E. Data, Data Collection and Experimental Validity}

The World Bank collected both a baseline survey and initial follow-up survey in the 360 sub-districts to assess PKH’s short-run program impacts (see Alatas 2011 for more details). These surveys were conducted using the same survey instruments as, and in tandem with, the evaluation of the Generasi community block grant program, which was being carried out in 300 separate sub-districts but was targeting similar indicators (see Olken, Onishi, and Wong 2014).

As shown in Appendix Table 1, 14,326 households (73,578 individuals) were surveyed at baseline in the 360 sampled sub-districts between June and August 2007. To create this sampling frame, 8 randomly selected villages were drawn from each sub-district, and then one sub-village was selected within each 
village. ${ }^{6}$ From within each village, four households were randomly selected from the government's interview lists, stratified such that two households included a pregnant or lactating mother or a married woman who was pregnant within the last two years and the other two included children aged 6-15 years of age. Note that since the survey was conducted in both treatment and control areas (and we do not know who would have received PKH in the control areas), households were randomly selected to be surveyed from the initial asset listing (not the beneficiary list), so not all households would have ultimately received PKH. There was very little attrition of households in the first follow-up that was conducted from October to December 2009: 13,971 (97.5 percent of baseline) were found and surveyed, and households that split and moved within the sub-district were also surveyed. Both the baseline and follow-up survey included a consumption module, demographics, assets, education, and health outcomes. Additionally, they included anthropometric data (height and weight measurements) for children aged 0 to 36 months in the baseline survey, and for children aged 0 to 60 months in both follow-up surveys.

This paper focuses on the medium-run follow-up, which we conducted from September to November 2013. The survey tracked the original households included in the baseline, collecting the same data as in the baseline and first follow-up. Overall household attrition was again low: 13,619 households or 95.1 percent of baseline households were found, with the attrition rates nearly identical across the treatment and control groups (see Appendix Table 1). ${ }^{7}$

While household attrition was low, it could be that some household members left the sub-district and thus are not accounted for in the survey. This is not an issue for the young children who were born after the baseline, since we measure all children present in any household we track, and we track 95 percent

\footnotetext{
${ }^{6}$ If there were less than 8 villages sampled in a sub-district (since there were not enough eligible households in enough villages), or if there were less than 5 potential households to survey in the sub-village, additional sub-villages from the same village were randomly selected.

${ }^{7}$ We followed entire households or household members that moved within the same sub-district. In addition, we surveyed 362 households that were added to the sampling frame in the two-year follow-up, and 751 households that were added in the six-year follow-up, in order to compensate for household attrition.
} 
of baseline households. Thus, attrition should likely not be a concern for outcomes like completed vaccination or stunting. ${ }^{8}$

However, it could, potentially, be relevant for the oldest children at baseline, who are now teenagers and young adults and could migrate for school, work, marriage, or other reasons. Thus, this could be more of an issue for results such as high school completion or teenage marriage. Therefore, in Appendix Table 2, we examine attrition for those who were initially aged 6-15 years in the baseline. We find and re-survey 90 percent at the two-year follow-up (Column 1) and 72 percent at the six-year follow-up (Column 2), but with no differential attrition between the treatment and control group in either survey. There do not appear to be large differences in attrition in the six-year survey between boys and girls (Columns 3 and 4).

We can further disaggregate by age at baseline to determine if attrition is worse for older children, who may be more likely to leave the household for work or marriage. In Appendix Table 3, we observe that attrition does indeed increase with baseline age. However, this attrition does not appear differential by treatment group: only 4 out of 40 regression coefficients are significant, which is consistent with chance. Moreover, for those household members who moved outside of the sub-district within the 12 months before the survey was conducted, we additionally have information on whether they migrated for work, school, or to follow a spouse. As shown in Appendix Table 4b, we observe no differences in the reasons for child migration across the treatment and control group. In short, while older children were more likely to have migrated than younger children, the probability of migration, as well as the reasons for doing so, do not appear to be associated with treatment status.

Finally, Appendix Table 6 shows that the final sample is balanced across treatments in terms of baseline characteristics. In Column 2, we provide the control group mean for the variable listed in that row, while Column 3 provides the mean for the treatment group. Column 4 provides the difference between the treatment and control for that variable (clustered by sub-district, which is the level of randomization) and

\footnotetext{
${ }^{8}$ An alternative concern for the younger children is that PKH affects differentially affects infant mortality and this biases the results for the young children. However, this does not appear to be the case: In Appendix Table 5, we show that there was no observable difference in miscarriage, stillbirth, or infant mortality rates in either follow-up survey.
} 
Column 5 provides this difference conditional on strata (districts). Of the 14 variables considered, no differences are statistically significant at the 10 percent level. Nonetheless, although our sample appears balanced, we included household-level baseline controls in our analysis for improved precision (discussed below).

\section{RESULTS}

In this section, we first outline our empirical strategy and show the first stage results. Next, we describe our results on health-seeking behaviors and health outcomes, and then we turn to educational and employment outcomes. Finally, we examine impacts on overall household consumption and asset acquisition.

\section{A. Empirical Strategy and First Stage Results}

As discussed above, while compliance with the randomization protocol was generally high, it was not perfect, and there were some control areas that were treated. In addition, households on Statistics Indonesia's interview lists were sampled in both treatment and control areas, but in treatment areas, only a subset of these households ultimately became beneficiaries of $\mathrm{PKH}$, as there was a subsequent screening step to determine PKH eligibility. ${ }^{9}$ Therefore, we conduct an instrumental variable analysis in which we instrument receipt of PKH (Received $_{h s d}$ ) with whether households were initially located in a treatment sub-district:

$$
Y_{h s d}=\beta_{0}+\beta_{1} \text { ReceivedPK } H_{h s d}+\boldsymbol{X}_{h s d}^{\prime} \boldsymbol{\gamma}+\alpha_{d}+\varepsilon_{h s d}
$$

$Y$ is the outcome of interest for household $h$ in sub-district $s$ in district $d$. ReceivedPK $H_{h s d}$ is a dummy variable for whether the household has ever received $\mathrm{PKH}$, while $\alpha_{d}$ is a set of district fixed effects. For additional precision, we include the following baseline control variables $\boldsymbol{X}_{h s d}$ : house roof type, wall type, floor type, head of household's education level, head of household works in agriculture, head of household

\footnotetext{
${ }^{9}$ We cannot restrict our sample to those who ever received PKH. We know who was ultimately chosen off the Statistics Indonesia list in the treatment group, but we do not know who would have been chosen in the control group.
} 
works in services, household has clean water, household has own latrine, household has square latrine, household has own septic tank, household has electricity from the state electric company (PLN), log monthly per-capita expenditure, and log household size. ${ }^{10}$ We cluster the standard errors by sub-district, the level of the randomization. We adjust $p$-values for multiple hypothesis testing within each panel of results using the stepdown method of Romano and Wolf (2005; 2016), and report any cases where such adjustment changes the statistical significance of the results. ${ }^{11}$

To potentially improve our precision, we run a second instrumental variable strategy in which we instrument whether a household has ever received PKH with the initial sub-district treatment status as well as the initial treatment status interacted with the baseline demographic and asset variables discussed above. We do this because we know that households were more likely to receive PKH if they were both in a treated sub-district and passed the proxy means test, which was a function of a household's assets; thus, this specification should theoretically increase our ability to predict who was ultimately a PKH beneficiary.

Table 1 provides our first-stage estimates. In Columns 1 and 3, we provide first-stage coefficients on the treatment variable for our simple instrumental strategy; in the last row, we also provide the F-statistic from a test of the instrument. Column 1 replicates the World Bank's estimates from the two-year followup for comparison, while Column 3 provides our six-year follow-up results. In Column 2 and 4, we provide the F-statistic for all instruments (treatment status and treatment status interacted with baseline controls) for the short-run and medium-run estimates (Appendix Table 7 provides the full set of coefficient estimates for the fully interacted regressions).

The regressions show a strong - and almost identical - first stage in both the short-run and mediumrun. By the two-year follow-up (Column 1), about 9 percent of the control group reported receiving PKH, with a 37.5 percentage point increase in the treatment group ( $p$-value less than 0.001$)$. The results are

\footnotetext{
${ }^{10}$ When we have missing baseline data, we fill in the controls with zero and create a dummy variable for the missing variable.

${ }^{11}$ We do this within each family of outcomes, grouped by column-panel. The finding qualitatively remain the same, with two changes - percentage of immunizations for age in Column 3 of Table 2 is no longer significant, and milk and egg expenditure in Column 2 of Table 7 is only significant at the 10 percent rather than the 5 percent level. For conciseness, we list these changes in significance after multiple hypothesis testing adjustment in the table notes.
} 
similar in 6-year follow-up (Column 3), with a 36.8 percentage point increase in the probability of receiving $\mathrm{PKH}$ in the treatment group relative to the 13.1 percent of households having ever received $\mathrm{PKH}$ in the control group ( $p$-value less than 0.001).

It is important to note that the randomization is at the subdistrict level, and hence control households come from other subdistricts. Virtually all health and education services (health clinics, schools) are contained within subdistricts, so spillovers across subdistricts are extremely unlikely in this context, and indeed, this was the reason the randomization was done at such a high level.

A second question is whether there are spillovers to non-treated households within treated subdistricts. This assumption of no within-subdistrict spillovers is important for the exclusion restriction implicit in estimating equation (1) with instrumental variables. While in other contexts this has been a concern - see, e.g. Angelucci and di Giorgi (2009) in the PROGRESA case, there are two reasons why even within-subdistrict spillovers seem very unlikely here. First, unlike PROGRESA, which treated over 60 percent of households in treatment villages, PKH was targeted at the poorest of the poor households, and as such treated a far smaller fraction of households in a village - in 2009, for example, the typical treated village had only 78 PKH beneficiary households out of a mean of 1200 households, meaning PKH treated only 6.5 percent of households in a village on average. General equilibrium effects (e.g. congestion at schools or health clinics, or positive spillovers through supply-side changes) are therefore likely to be very small in our case given how small the share of treated households is. ${ }^{12}$ Second, our alternate identification strategy uses baseline assets interacted with sub-district-level treatment status to predict treatment at the individual level, not at the aggregate level; as shown below, however, this produces very similar results to the univariate treatment-vs-control sub-district instrument (and in particular, these results are not

\footnotetext{
${ }^{12}$ Moreover, given this, one would expect that the average effect on a non-beneficiary household is therefore likely at least an order-of-magnitude smaller than the average effect on beneficiary households. Since our household survey intentionally sampled households who were likely to be beneficiaries, beneficiary households about 50 percent of the sampled households in the treatment area. This means that the average effect in our sampled households will be driven almost entirely by the effect on treated households.
} 
systematically smaller than the univariate results), suggesting empirically that spillovers are very small in our context.

\section{B. Impacts on Incentivized Health-Seeking Behaviors}

In Table 2, we report IV estimates of the effect of receiving PKH on incentivized health-seeking behaviors. We estimate separate regressions for each outcome of interest listed in each row. Our key estimates from the six-year follow-up survey are shown in Columns 3 and 4; each cell presents the IV effect of PKH treatment analyzed using equation (1). For ease of comparability, in the first two columns we show the results from the two-year survey conducted by the World Bank, which we re-analyzed using the same IV specification as (1). In Columns 1 and 3, we instrument ever receiving PKH with the sub-district-level treatment vs. control randomized assignment, while in Columns 2 and 4 we instrument receiving PKH with the randomized treatment assignment and the treatment assignment interacted with baseline characteristics. All standard errors are clustered at the sub-district level, and we include household level baseline controls and strata (district) fixed effects as control variables. ${ }^{13}$

Note that for many of these health-seeking behaviors, they could have easily been moved in the short-run (e.g. pre-natal visits, or good deliveries) and, indeed, Table 2 shows significant improvements across many of the indicators in the short-run.

However, our analysis also shows continued effects of PKH on health-seeking behaviors in the medium-run, particularly with regard to maternal health-seeking behaviors. In Panel A, we first examine health-seeking outcomes for women who became pregnant or gave birth within the 24 months prior to each follow-up survey. We find that PKH continued to have large, positive effects on the probability that

\footnotetext{
${ }^{13}$ Our results are robust to the model specification choices that we made. For example, in Appendix Tables 8 and 9, we replicate Tables 2 and 3 using "currently receiving" PKH, rather than "ever received" PKH, as our variable of interest, because some households received PKH in the two-year follow-up survey but had stopped receiving it by the six-year follow-up; the results look nearly identical (which is not surprising given the overlap of households in both categories is high). Similarly, in Appendix Tables 10, 11, and 12, we replicate Columns 1 and 3 from Tables 2, 3, and 4, but drop baseline controls (we cannot drop baseline controls from our IV strategy in Columns 2 and 4 since they rely on the interactions of treatment status with the controls). Again, we find similar coefficients, but sometimes we lose some statistical precision when omitting the baseline controls.
} 
childbirths were assisted by trained personnel (doctors or midwives) in the six-year follow-up, and that deliveries were more likely take place in a health facility for those who have given birth. In fact, PKH led to a 13 to 17 percentage point increase in delivery at a health facility at the six-year follow-up (18 to 24 percent increase; $p$-value 0.045 in Column 3 and 0.01 in Column 4), even qualitatively larger than the impact seen at two years (8 - 11 percentage points; 19 to 25 percent increase; $p$-values 0.10 and 0.07 ). However, unlike in the short-run, we do not find impacts on pre- and post-natal visits. This could be because the control group increased their overall number of visits in the intervening years (for example, the control mean increased from 6.6 to 7.3 pre-natal visits) and essentially caught up to the treatment group. In terms of the care women and children received, we observe no difference in receiving a full set of iron pills during pregnancy, either in the two- or six-year follow-up.

Health inputs into young children (Panel B) also appear to have improved in the medium-run for children who had ever been covered by PKH since the baseline survey. Importantly, while there was no observable impact on immunizations in the two-year follow-up survey for children in our baseline sample, we find that immunization rates increased by the six-year follow-up survey ( $p$-values 0.11 and 0.02 ). In fact, we observe about a 5 percentage point increase in the percent of necessary immunizations completed for age (p-values .09 and .04). We observe no increase in the number of times children between the ages of 6 months and 2 years received Vitamin A. However, we observe increases in the number of times a child was weighed by a health professional in the last 3 months (for those aged 0 to 60 months), though these increases are no longer significant and smaller in the six-year follow-up ( $p$-values 0.19 and 0.17 ) compared to the two-year follow-up ( $p$-values both less than 0.01).

\section{Impacts of PKH on Health Outcomes}

Anthropometric Impacts. The results thus far have shown that health-seeking behaviors continued to be positively affected by the PKH program, on top of some overall improvements in health-seeking behaviors over this period. This implies that at the time of the six-year survey, young children (those under 5 years old) had spent their entire lives accessing improved health services at various points in their life cycle. A 
natural question is whether this increased health utilization accumulated and led to changes in health outcomes.

We examine this question in Table 3. The regression specifications and table format are similar to those of Table 2. We explore anthropometric outcomes for children aged 0 to 60 months in Panel A, as well as their parent-reported acute health outcomes in Panel B. We then examine maternal knowledge outcomes pertaining to early child health in Panel C.

We start by examining measures of stunting. Stunting is considered a measure of cumulative health investments during the first few years of life (Hoddinott et al. 2013; Jayachandran and Pande 2017); it is also thought to be correlated with worse cognitive and economic outcomes later in life (Case and Paxson 2008; Gluwwe and Miguel 2008; Hoddinott, Maluccio, Behrman et al. 2011; Guven and Lee 2013), and as such is a major policy interest. We follow WHO definitions and define stunting as being more than 2 standard deviations below the WHO-standardized height-for-age median; severe stunting is defined as being more than 3 standard deviations below the WHO-standardized height-for-age median.

We observe very large reductions in stunting among children aged 0 to 60 months in the six-year follow-up survey. Stunting declined by roughly 9 to 11 percentage points, representing a 23 to 27 percent reduction in the probability of being stunted ( $p$-values 0.02 and less than 0.01 ). Severe stunting declined by approximately 10 percentage points (p-values both less than 0.01 ), representing a 56 to 62 percent reduction. ${ }^{14}$ Both boys and girls benefited from PKH in terms of decreased stunting and severe stunting, although the point estimates are slightly larger in magnitude for boys than for girls (see Appendix Table 13). While the point estimates indicate stunting reductions of about 2 to 3 percentage points after the program had been in effect for two years, these estimates are not statistically significant ( $p$-values 0.42 and $0.45)$.

\footnotetext{
${ }^{14}$ Appendix Figure 5 estimates the impacts on stunting non-parametrically by child age, and finds similar reductions in stunting across the 0 - to 60 -month-olds in our sample. If anything, the figures suggest somewhat larger reductions in stunting on older cohorts.
} 
We observe no impacts on malnourishment overall (weight-for-age more than 2 standard deviations below WHO standards) — which responds more quickly to health investments — in either the two- or sixyear follow-up (Panel A of Table 3). However, it is worth noting that when we break down the anthropometric results by gender (see Appendix Table 13), we observe some evidence of reductions in malnourishment for boys ( $p$-values 0.37 and 0.03 for malnourishment; 0.16 and 0.03 for severe malnourishment), which could be related to the larger reductions in stunting observed for boys. ${ }^{15}$

Potential mechanisms for stunting effects. Given that PKH is a bundled intervention (cash + incentives) that could affect many aspects of family life, it is hard to disentangle which specific channels could fully account for the reductions in stunting. However, we next try to explore different factors that could affect the results.

First, it could be that the increased health-seeking behaviors (such as improved delivery and increases in immunizations) that we observe in Table 2 could contribute to reductions in stunting, and it is possible that these had cumulative effects over time.

Second, we explore whether reported illness of the children has declined, under the hypothesis that sick children would have more stunted growth paths. We investigate this in Panel B of Table 3. The results show no declines in reported acute illness rates, such as diarrhea, fevers, or coughs for children under 5 in either survey wave; if anything, the point estimates suggest increases in acute illness in the two-year followup. To the extent we can measure these types of illness in our data, they thus do not appear to change in the data in response to $\mathrm{PKH}$.

\footnotetext{
${ }^{15}$ As Kanpal (2016) notes, most experimental evaluations to-date of CCTs have not shown large effects on stunting. There are two exemptions. Fernald et al. (2008) looks at stunting in PROGRESA in 2003, comparing families who were initially part of the 1997 with those in the control group (that received PROGRESA starting 18 months later) and find that longer exposure to PROGRESA led to reductions in stunting. Kanpal (2016) experimentally measures the effect the Philippines's Pantawid program on stunting 30-31 months after its introduction, and finds similar effects for children aged 6 months to 36 months. They argue that part of the reasons for the impact could be the program's focus on nutrition (particularly dairy) in family development sessions.
} 
Next, we explore whether mother knowledge and maternal health behaviors changed as a result of PKH. These results are presented in Panel C of Table 3. We do observe that mothers in the treatment group were much more likely to be able to report their child's birthweight in our survey, perhaps a function of increased deliveries in facilities or PKH's focus on healthy child weight. We do not, however, observe any changes in overall maternal knowledge of behaviors that could affect child health and nutrition (see Appendix Table 14 for a breakdown of the index). ${ }^{16}$ Moving to maternal health behaviors, we show no changes in self-reported breast-feeding practices (although these measures are fairly high to begin with) and no observable additional household investment in sanitation (e.g. piped water, toilets, electricity) that could affect child health (see Appendix Table 14).

Finally, we explore changes in nutrition (see Appendix Table 16). We do find changes in child nutritional protein intake in response to $\mathrm{PKH}$, concentrated in dairy and eggs: we find that children 18-60 months were roughly 10 to 11 percentage points more likely to have consumed milk ( $p$-values 0.01 and less than 0.01 ), and 10 to 12 percentage points more likely to have consumed eggs ( $p$-values both less than 0.01), in the week prior to the two-year follow-up survey. We do not find similar results at the 6 year endline, though confidence intervals cannot reject substantial positive effects.

On net, while unpacking mechanisms is challenging, the constellation of results here - the increase regular weight checks, increased maternal knowledge of birthweight, and increase protein consumption, combined with the increase in weight-for-age for boys - all point to prolonged attention to weight and nutrition over the early lifecycle as a potentially important channel for these results.

\section{Impacts on Incentivized Primary and Junior Secondary Education}

\footnotetext{
${ }^{16}$ In Appendix Table 15, we also explore whether young mothers (less than age 35) have increased autonomy over decision-making, particularly around education and health. We observe that most families make decisions about children together-with the mother reporting being involved in about 75-80 percent of these important family-life decisions - and this increased further as a result of PKH. Women also reported being more likely to make decisions alone regarding children's health, both in the two- and six-year follow-up.
} 
The second component of the PKH incentives are focused on education. We start by examining whether the program continued to have effects in the six-year follow-up on the children currently explicitly targeted by PKH: in Table 4, we look at enrollment and attendance for children aged 7-15 (Panel A), and then disaggregate further by age 7-12 (Panels B and C) and age 13-15 (Panel D). In Section III-F., we examine whether these educational investments had cumulative effects beyond the target period.

Overall, we find increases in enrollment for all children, aged 7 to 15 (Panel A). In particular, we find a 4 percentage point increase in enrollment rates in the six-year follow-up ( $p$-values both less than 0.01). Since 92.4 percent of control group children were enrolled in school, the 4 percentage point increase in enrollment rates represents a 53 percent decrease in the fraction of students who were not enrolled in school; that is, PKH eliminated more than half of non-enrollments. This effect is similar (if slightly smaller) to what was observed at two years - a 6.4 to 6.8 percentage point increase in enrollments ( $p$-values both less than 0.01), which represents a 66 to 70 percent decline in the non-enrollment rate. Moreover, we observe increases in the percentage of children who report attending school at least 85 percent of the time in the last two weeks, with effect sizes quite similar in both the two- and six-year follow-ups ( $p$-values less than 0.01 for both specifications in each follow-up survey). ${ }^{17}$

Looking at the effects by age group, we see that the six-year effects are concentrated among older students (Panel D). For students aged 13-15, we see increases in school enrollments of 8 to 9 percentage points ( $p$-values both less than 0.01), representing a 47 to 52 percent decline in the non-enrollment rate. For students aged 7-12, we see increases of 1.2 to 1.5 percentage points ( $p$-values 0.11 and 0.05 ). Since the control group enrollment rate for this age group is already high, at 97.2 percent, these effects also represent similarly sized (43 - 54 percent) reductions in the non-enrollment rate. In sum, though the effects are

\footnotetext{
${ }^{17}$ Note that this attendance measure is defined as 0 for those non-enrolled in school. This measure therefore captures the combination of enrollment and attendance decisions, since both can respond to PKH receipt. Appendix Table 17 examines the six-year effects for boys and girls separately. As shown in Panel B, younger boys receiving PKH are more likely to be in school, while we find no effect for younger girls-however, girls have very high rates of enrollment to begin with (98\% are enrolled in some form of school). While somewhat larger in magnitude for older boys than for older girls, we nonetheless observe treatment effects of PKH on the enrollment and attendance of both older boys and girls (Panel D).
} 
slightly smaller than were observed after two years, the conditional cash transfer remained highly effective at reducing non-enrollment in school for those in the targeted age category.

\section{E. Impacts on Child Labor}

In Table 5, we examine whether these gains in schooling are associated with changes in child labor for the same age groups. We do not find any changes for young children aged 7 to 12 (Panel A). However, this is not surprising as only 1.6 percent of children in the control group report working for a wage at all, and only 0.4 percent report working more than 20 hours for wage in the past month. However, for older children (Panel B), we find that the PKH program reduced the fraction of children engaged in wage work by between 3 and 4.4 percentage points ( $p$-values 0.10 and 0.03 ). This represents a reduction of $34-48$ percent. For those working extensively, which we define as working for a wage at least 20 hours in the past month, the effects are similar: reductions of between 2.4 and 3.0 percentage points (p-values 0.12 and 0.08 ), representing a decline of 44 to 55 percent. As shown in Appendix Table 18, these reductions in wage work are primarily found for boys, who are more likely to be working for a wage in general than girls are. ${ }^{18}$

The fact that we see both substantial increases in school enrollments and declines in wage work for the same age groups suggests that the two effects may be related. This could be both through the children's time budget constraint (time spent in school is time spent not working), or due to income effects from the PKH cash transfer (the income from the cash transfer means the family does not have as strong a need for the child's income). While it is hard to distinguish these effects, several facts are worth noting. In Appendix Table 20, we show that PKH led to a decline in the number of students who were both enrolled in school and working for a wage at the same time. We also see very small declines in the number of students who were not enrolled but were working. Combined, these facts suggest that most of the effects we see on enrollment and work are not coming from a time-budget constraint, where students are induced to switch

\footnotetext{
${ }^{18}$ In Appendix 19, we explore alternative measures of non-wage work. In the medium-run, we observe some reductions in working more than 20 hours a month for a family business in for those aged 13-15 (but this is not significant in all specifications) and no effect on "helping out at home."
} 
from work to school. While these facts do not necessarily separate price from incentive effects, they are suggestive evidence that the income from the transfer may be a non-trivial part of the story.

\section{F. Impacts on High School Education, Labor, Early Marriage, and Early Fertility}

Our final set of results for children explores outcomes for children who were aged 9 to 15 when PKH was initially rolled out, and hence are between ages 15 and 21 at the time of the six-year follow-up. This allows us to explore the cumulative effects of PKH on final educational attainment and early adulthood outcomes after the incentives have ended. These results are presented in Table 6. Note that we continue to provide short-run outcomes, when possible, for comparison. ${ }^{19}$

We begin by exploring educational outcomes for this cohort, shown in Table 6, Panel A. We find large increases in the probability of those aged 15 to 17 attending any kind of school in the six-year followup ( $p$-values both 0.02 ), with some of this effect driven by increases in high school enrollment. ${ }^{20}$ We also find some evidence of an increase in high school completion rates for those aged 18 to 21 (4 to 7 percentage points, $p$-values 0.07 and 0.24 ). As shown in Appendix Table 22, most of the increases in educational attainment for these age categories are driven by boys, who show very large impacts on high school enrollment (9 to 13 percentage points, representing a 27 to 38 percent increase; $p$-values 0.04 and less than 0.01 ) and completion rates (4.9 to 9.7 percentage points; 21 to 42 percent increase; $p$-values 0.19 and 0.03 ). We find no impact on high school enrollment or completion rates for girls.

We then explore work outcomes for this age group, shown in Panel B of Table 6. We find no impacts on the probability of wage work, for either 16- to17-year-olds or 18- to 21-year-olds. As shown in Appendix Table 22, we find no effect for either boys or girls. For 16- to 17-year-olds, one might expect a decrease in wage work due to the increases in school enrollment documented above; while we do not

\footnotetext{
${ }^{19}$ In particular, we omit outcomes for ages 18 to 21 from our reported two-year regressions, because virtually no respondents who were aged 9 to 15 at baseline had reached age 18 by the time of the two-year follow-up survey.

${ }^{20}$ As shown in Appendix Table 21, we observe increases in 15-year-olds and 17-year-olds attending any type of school. The high school effect appears largely driven by 17-year-olds.
} 
observe this, as shown in Panel A of Appendix Table 23, we do observe some decreases in helping out with the family business or housework (particularly for girls).

For 18- to 21-year-olds, who are more likely to be out of school and who are more likely to have completed a high school education, we may have expected higher employment rates for wage work. However, this does not appear to be the case. We do observe that the boys within this age category were more likely to help out with the family business (Columns 3 and 4 of Panel B of Appendix Table 23), while girls were somewhat less likely to help out in any family business or housework (Columns 5 and 6). Note that, as discussed earlier, these results do not appear to be driven by attrition, as we do not observe differences between treatment and control either in the probability of leaving the district for these age groups (Appendix Table 4) nor in the probability of leaving the district for work (Appendix Table 4b). It is worth noting, however, that these 18- to 21-year-olds were already teenagers at the time PKH started, and thus spent fewer of their formative years in the program than the young children for whom we observe reductions in stunting.

In Panel C, we explore whether PKH led to changes in age of marriage. Age of marriage could be delayed from the income effect of $\mathrm{PKH}$, or from a delay in marriage due to the practical side of being enrolled in school longer. However, we find no evidence that PKH changed the propensity to marry for those aged 16 to 17, or for those aged 18 to 21. Finally, we investigate changes in fertility (Appendix Table 24), and while we qualitatively observe postponement of births—decreases in fertility for girls aged 16-17 and increases for those aged 18-21—we cannot reject that these coefficients are different from zero.

\section{G. Cumulative impacts on recipient households: Consumption, Work and Assets}

PKH provides a small amount of cash to households each and every quarter for around 6 years. The cash payment is around 7 to 15 percent of total household consumption, cumulatively adding up to between $\$ 360$ and $\$ 1320$ per household. ${ }^{21}$ The next question we ask is whether this assistance was large enough to have

\footnotetext{
${ }^{21}$ Note that PKH initially aimed to provide beneficiaries with a cash transfer equal to about 15 to 20 percent of their overall household consumption level. However, the nominal values of the transfer remained fixed, so the real value
} 
a "transformative effect" on households, shifting them out of poverty, having a "transformative effect" One mechanism for this could be that households save part of the transfers over time, and use this to invest in productive assets. For example, Gertler, Martinez, and Rubio-Codina (2012) find that PROGRESA invested a fraction of their accumulated transfers in productive assets.

To examine this, in Table 7, we examine the impacts of PKH on household consumption, adult employment, and household assets. ${ }^{22}$ Panel A examines the impact on overall log per-capita consumption, food expenditures, spending on alcohol and tobacco, and spending on health and education. We find no statistically detectable impacts on any of these outcomes. Specifically, while we observe positive impacts of $\mathrm{PKH}$ on overall household consumption and the other associated expenditure items, we cannot distinguish these measured impacts from zero; on the other hand, we cannot reject an increase of consumption equal to the amount of the PKH transfer at the six-year follow-up. Note that the fact that we cannot detect changes in consumption due to $\mathrm{PKH}$ is not driven by heads of household choosing to work less (and thus reducing consumption): as shown in Panel B, we find no effect on whether the head of household was employed. In fact, even in the control group, nearly 94 percent of the control group was employed regardless.

We also examine whether PKH led to increases in assets as PKH transfers accumulated over time (Panel B). We show that there was no change in land ownership; however, this is unsurprising as more than 90 percent of the control group owned land. However, we also find no observable effect on assets where we might expect more movement, such as livestock ownership.

The key point of these results is that we fail to find any measurable effects on the material consumption of the recipient households themselves. While we cannot rule out effects on consumption equal to the size of the transfer, the key point is that we do not see transformational effects for these households. To the extent that the CCT program leads to substantially large changes in material household

of the transfer declined over time: our estimates suggest that $\mathrm{PKH}$ payments were about 7 percent of household consumption by the six-year follow-up.

${ }^{22}$ In Appendix Table 25, we disaggregate expenditure outcomes by province and again find noisy estimates. Nonetheless, the increase in log consumption appears largest in the relatively poorer province of East Nusa Tenggara. 
welfare, these will likely come through the effects on the next generation, who experience increased health and education, rather than a reduction in overall poverty of the current generation.

\section{CONCLUSION}

The decision to redistribute through targeted transfers is a complex one. Some arguments are at core ethical, arguing that a society should protect the vulnerable and give them some additional help. Others are economic, arguing, for example, that increased spending by poorer households shores up economic demand, or that transfers allow households to make business investments that can transformatively increase household income and reduce poverty. Still others make arguments that are based on concerns about inequality and its detrimental effects on intergenerational poverty, with transfers as a mechanism to help increase investments in child health and education.

In this paper, we estimate the six-year effects of a large-scale, government-run conditional cash transfer program $(\mathrm{PKH})$, which provides moderately sized, regular, financial assistance to households that adhere to conditions that aim to improve investments in child health and education. We find that even though the program has been running for six years—-without any researcher involvement in later years, and with a changing economic landscape over time- - the program continues to promote health and educational investments in children explicitly targeted by the program. For example, at six years, we continue (as compared to a two-year follow-up) to observe increases in usage of trained health professionals for childbirth, and PKH continues to halve the share of children aged 7 to 15 who are not enrolled in school.

Perhaps even more importantly, for children who have grown up under $\mathrm{PKH}$, we also begin to observe impacts on outcomes that may require cumulative investments: for example, six years later, we observe large reductions in stunting and some evidence of increased high school completion rates. While this does not yet translate to increases in employment for individuals who have just started to age out of $\mathrm{PKH}$, these are children who were already teenagers at the time PKH started, and have thus spent fewer of their formative years in the program. The stunting results suggest that effects may be larger in the very long-run for children who benefited from the program during early childhood. 
In contrast, we do not observe any impact on $\mathrm{PKH}$ beneficiaries' current consumption, employment, or assets—suggesting that the additional help that $\mathrm{PKH}$ provides does not transformatively reduce poverty for those currently on the program. Rather, given that our results show that CCTs help poor households make significant investments in their children's health and education, an important part of the economic gains of CCTs likely could come from reductions in the intergenerational transmission of poverty. 


\section{WORKS CITED}

Alatas, Vivi. 2011. Program Keluarga Harapan: Impact Evaluation of Indonesia's Pilot Household Conditional Cash Transfer Program. Washington, DC: World Bank.

Angelucci, Manuela, and Giacomo De Giorgi. 2009. "Indirect Effects of an Aid Program: How Do Cash Transfers Affect Ineligibles' Consumption?" American Economic Review, 99(1): 486-508.

Barham, Tania, Karen Macours, and John Maluccio. 2017. "Are Conditional Cash Transfers Fulfilling Their Promise? Schooling, Learning, and Earnings after 10 Years.” CEPR Discussion Paper DP11937.

Behrman, Jere R., and Petra E. Todd. 1999. "Randomness in the Experimental Samples of PROGRESA—Education, Health, and Nutrition Program.” IFPRI Discussion Paper.

Banerjee, Abhijit, Rukmini Banerji, James Berry, Esther Duflo, Harini Kannan, Shobhini Mukerji, Marc Shotland, and Michael Walton. 2017. "From Proof of Concept to Scalable Policies: Challenges and Solutions, with an Application.” Journal of Economic Perspectives, 31(4): 73-102.

Barrera-Osorio, Felipe, Leigh L. Linden, and Juan Saavedra. 2017. “Long Term Educational Consequences of Alternative Conditional Cash Transfer Designs: Experimental Evidence from Colombia.” American Economic Journal: Applied Economics, forthcoming.

Bastagli, Francesca, Jessica Hagen-Zanker, Luke Harman, Valentina Barca, Georgina Sturge, and Tanja Schmidt. 2016. “Cash Transfers: What Does the Evidence Say?” Overseas Development Institute Report.

Blattman, Chris, Michael Faye, Dean Karlan, Paul Niehaus, and Chris Udry. 2017. "Cash as Capital.” Stanford Social Innovation Review.

Bold, Tessa, Mwangi Kimenyi, Germano Mwabu, Alice Ng’ang’a, and Justin Sandefur. 2015. "Interventions and Institutions: Experimental Evidence on Scaling up Education Reforms in Kenya.” Unpublished paper.

Case, Anne, and Christina Paxson. 2008. "Stature and Status: Height, Ability, and Labor Market Outcomes.” Journal of Political Economy 116 (3): 499-532.

Dearden, Lorraine, and Martin Ravallion. 1988. “Social Security in a 'Moral Economy': An Empirical Analysis for Java.” Review of Economics and Statistics 70(1): 36-44.

Fernald, Lia C.H., Paul Gertler, and Lynnette Neufeld. 2008. "Role of Cash in Conditional Cash Transfer Programmes for Child Health, Growth, and Development: An Analysis of Mexico's Oportunidades.” Lancet 371(9615): 828-837.

Filmer, Deon, and Norbert Schady. 2014. "The Medium-Term Effects of Scholarships in a LowIncome Country.” Journal of Human Resources 49(3): 663-694. 
Gertler, Paul. 2004. "Do Conditional Cash Transfers Improve Child Health? Evidence from PROGRESA's Control Randomized Experiment.” American Economic Review 94(2): 336-341.

— Sebastian Martinez, and Marta Rubio-Codina. 2012. "Investing Cash Transfers to Raise Long-Term Living Standards.” American Economic Journal: Applied Economics 4(1): 164-192.

Glewwe, Paul, and Edward A. Miguel. 2008. "The Impact of Child Health and Nutrition on Education in Less Developed Countries.” In Handbook of Development Economics, Vol. 4, edited by T. Paul Schultz and John Strauss, 3561-3606. Amsterdam: Elsevier.

Guven, Cahit, and Wang Sheng Lee. 2013. "Height and Cognitive Function at Older Ages: Is Height a Useful Summary Measure of Early Childhood Experiences?” Health Economics 22(2): 224-233.

Hoddinott, John, Harold Alderman, Jere Behrman, Lawrence Hadadd, and Susan Horton. 2013. “The Economic Rationale for Investing in Stunting Reduction.” Maternal \& Child Nutrition 9(S2): 69-82.

Hoddinott, John, Jere R. Behrman, John A. Maluccio, Paul Melgar, Agnes R. Quisumbing, Manuel Ramirez-Zea, Aryeh D. Stein, Kathryn M. Yount, and Reynaldo Martorell. 2013. “Adult Consequences of Growth Failure in Early Childhood.” American Journal of Clinical Nutrition 98(5): 1170-78.

Jayachandran, Seema, and Rohini Pande. 2017. "Why are Indian Children So Short? The Role of Birth Order and Son Preference.” American Economic Review 107(9): 2600-2629.

Kandpal, Eeshani, Harold Alderman, Jed Friedman, Deon Filmer, Junko Onishi, and Jorge Avalos. 2016. "A Conditional Cash Transfer Program in the Philippines Reduces Severe Stunting." Journal of Nutrition 146(9): 1793-1800.

Kugler, Adriana D., and Ingrid Rojas. 2018. "Do CCTs Improve Employment and Earnings in the Very Long-Term? Evidence from Mexico.” NBER Working Paper 24248.

Levy, Santiago. 2006. Progress Against Poverty: Sustaining Mexico's PROGRESAOportunidades Program. Washington, DC: Brookings Institution.

Molina-Millan, Teresa, Tania Barham, Karen Marcours, John A. Maluccio, and Marco Stampini. 2016. "Long-Term Impacts of Conditional Cash Transfers in Latin America: Review of the Evidence.” Inter-American Development Bank working paper.

Muralidharan, Karthik, and Paul Niehaus. 2017. “Experimentation at Scale.” Journal of Economic Perspectives, 31(4): 103-24. 
Olken, Benjamin A., Junko Onishi, and Susan Wong. 2014. "Should Aid Reward Performance? Evidence from a Field Experiment on Health and Education in Indonesia." American Economic Journal: Applied Economics 6(4): 1-34.

Parker, Susan W., and Tom S. Vogl. 2017. "Do Conditional Cash Transfers Improve Economic Outcomes in the Next Generation? Evidence from Mexico.” Working paper.

Romano, Joseph P., and Michael Wolf. 2005. "Stepwise Multiple Testing as Formalized Data Snooping." Econometrica 73(4): 1237-82.

—. 2016. "Efficient Computation of Adjusted p-Values for Resampling-Based Stepdown Multiple Testing.” Working Paper.

UNICEF. 2013. Improving Child Nutrition: The Achievable Imperative for Global Progress. New York: UNICEF.

World Bank. 2018. The State of Social Safety Nets 2018. Washington, DC: World Bank. 
Table 1: First-Stage Regressions, Household Level

\begin{tabular}{lccccc}
\hline & \multicolumn{2}{c}{ 2-Year } & & \multicolumn{2}{c}{ 6-Year } \\
\cline { 2 - 3 } \cline { 5 - 6 } Outcome: Ever Received PKH & Lottery Only & Lottery + Assets & & Lottery Only & Lottery + Assets \\
\hline Treatment & $0.375^{* * *}$ & & & $0.368^{* * * *}$ & \\
& $(0.017)$ & & & $(0.017)$ & \\
& 14757 & 14757 & & 15667 & 15667 \\
Observations & 0.258 & 0.291 & & 0.242 & 0.270 \\
$R^{2}$ & 0.091 & 0.091 & & 0.131 & 0.131 \\
Control Mean & 507.797 & 59.741 & & 456.783 & 56.969 \\
F-statistic & & &
\end{tabular}

Note: This table reports first-stage regressions of PKH receipt status ("Ever Received PKH") on baseline treatment assignment. Columns 1 and 2 report results for the 2-year follow-up survey and Columns 3 and 4 report results for the 6-year follow-up survey. In Columns 1 and 3 ("Lottery Only"), we use only the baseline treatment assignment as our instrument. In Columns 2 and 4 ("Lottery + Assets"), we use as our instrument the baseline treatment assignment variable as well as its interaction with all baseline controls. In the final row, we report F-statistics from a Wald test of simple (Columns 1 and 3) or joint (Columns 2 and 4) hypotheses involving the strength of our chosen instruments. Baseline controls include the following: household roof type, wall type, floor type, head of household's education level, head of household works in agriculture, head of household works in services, household has clean water, household has own latrine, household has square latrine, household has own septic tank, household has electricity from PLN, $\log$ monthly per-capita expenditure, and log household size. Includes district (kabupaten) fixed effects. Standard errors are clustered by sub-district.

$* p<0.1 * * p<0.05 * * * p<0.01$. 
Table 2: IV Effect of PKH on Health-Seeking Behaviors

\begin{tabular}{|c|c|c|c|c|}
\hline \multirow[b]{2}{*}{ Outcome: } & \multicolumn{2}{|c|}{ 2-Year } & \multicolumn{2}{|c|}{ 6-Year } \\
\hline & $\begin{array}{c}\text { (1) } \\
\text { Lottery Only }\end{array}$ & $\begin{array}{c}\text { (2) } \\
\text { Lottery + Assets }\end{array}$ & $\begin{array}{c}\text { (3) } \\
\text { Lottery Only }\end{array}$ & $\begin{array}{c}\text { (4) } \\
\text { Lottery + Assets }\end{array}$ \\
\hline \multicolumn{5}{|l|}{ Panel A: Maternal Health-Seeking Behaviors } \\
\hline \multirow[t]{4}{*}{ Number of pre-natal visits } & $1.107 * *$ & $1.000^{* *}$ & 0.771 & 0.485 \\
\hline & $(0.512)$ & $(0.424)$ & $(0.647)$ & $(0.520)$ \\
\hline & 2,771 & 2,771 & 2,855 & 2,855 \\
\hline & 6.585 & 6.585 & 7.286 & 7.286 \\
\hline \multirow[t]{4}{*}{ Good assisted delivery } & $0.115^{* *}$ & $0.130 * *$ & $0.233 * * *$ & $0.162 * * *$ \\
\hline & $(0.056)$ & $(0.051)$ & $(0.059)$ & $(0.059)$ \\
\hline & 2,100 & 2,100 & 2,154 & 2,154 \\
\hline & 0.640 & 0.640 & 0.770 & 0.770 \\
\hline \multirow[t]{4}{*}{ Delivery at health facility } & $0.112^{*}$ & 0.086 & $0.171 * * *$ & $0.130 * *$ \\
\hline & $(0.062)$ & $(0.052)$ & $(0.066)$ & $(0.065)$ \\
\hline & 2,100 & 2,100 & 2,154 & 2,154 \\
\hline & 0.457 & 0.457 & 0.725 & 0.725 \\
\hline \multirow[t]{4}{*}{ Number of post-natal visits } & $1.024 * *$ & $1.199 * * *$ & 0.258 & 0.141 \\
\hline & $(0.400)$ & $(0.343)$ & $(0.419)$ & $(0.327)$ \\
\hline & 2,100 & 2,100 & 2,154 & 2,154 \\
\hline & 1.391 & 1.391 & 1.970 & 1.970 \\
\hline \multirow[t]{4}{*}{$90+$ iron pills during pregnancy } & 0.025 & 0.009 & -0.035 & -0.035 \\
\hline & $(0.049)$ & $(0.042)$ & $(0.044)$ & $(0.040)$ \\
\hline & 2,202 & 2,202 & 2,265 & 2,265 \\
\hline & 0.179 & 0.179 & 0.131 & 0.131 \\
\hline \multicolumn{5}{|l|}{ Panel B: Child Immunizations and Health Visits } \\
\hline \multirow[t]{4}{*}{ All immunizations complete for age } & 0.033 & 0.025 & 0.078 & $0.100 * *$ \\
\hline & $(0.044)$ & $(0.040)$ & $(0.048)$ & $(0.044)$ \\
\hline & 7,769 & 7,769 & 9,989 & 9,989 \\
\hline & 0.425 & 0.425 & 0.529 & 0.529 \\
\hline \multirow[t]{4}{*}{$\%$ of immunizations received for age } & 0.038 & 0.039 & $0.048^{*}$ & $0.054 * *$ \\
\hline & $(0.029)$ & $(0.028)$ & $(0.029)$ & $(0.027)$ \\
\hline & 7,769 & 7,769 & 9,989 & 9,989 \\
\hline & 0.754 & 0.754 & 0.786 & 0.786 \\
\hline \multirow[t]{4}{*}{ Times received Vitamin A (6 months - 2 years) } & -0.022 & -0.170 & -0.095 & 0.101 \\
\hline & $(0.208)$ & $(0.243)$ & $(0.205)$ & $(0.156)$ \\
\hline & 1,428 & 1,428 & 1,498 & 1,498 \\
\hline & 1.639 & 1.639 & 1.817 & 1.817 \\
\hline \multirow[t]{4}{*}{ Times weighed in last 3 months ( $0-60$ months) } & $0.919 * * *$ & $0.871 * * *$ & 0.250 & 0.238 \\
\hline & $(0.130)$ & $(0.115)$ & $(0.192)$ & $(0.178)$ \\
\hline & 7,934 & 7,934 & 4,373 & 4,373 \\
\hline & 1.790 & 1.790 & 1.954 & 1.954 \\
\hline
\end{tabular}

Note: Each row in this table represents a separate outcome variable, with regression specifications corresponding to each column of the table. Each table entry includes: 1) the regression coefficient, 2) the cluster-robust standard error, 3) the number of observations, and 4) the control mean. Panel B regressions include age-bin controls for each month of age up to 1 year, and for each quarter-year of age for ages 1 and above, in addition to baseline controls and fixed effects listed in Table 1. Adjusting $p$-values to control the family-wise error rate within each panel, as described by Romano and Wolf (2005; 2016), the effect on "\% of immunizations received for age" in Column 3 is no longer significant; all other significant effects remain significant. Standard errors, clustered by sub-district, are shown in parentheses.

$* p<0.1 * * p<0.05 * * * p<0.01$. 
Table 3: IV Effect of PKH on Child Nutrition and Health Outcomes, 0-60 Months

\begin{tabular}{|c|c|c|c|c|}
\hline \multirow[b]{2}{*}{ Outcome: } & \multicolumn{2}{|c|}{ 2-Year } & \multicolumn{2}{|c|}{ 6-Year } \\
\hline & $\begin{array}{c}\text { (1) } \\
\text { Lottery Only }\end{array}$ & $\begin{array}{c}\text { (2) } \\
\text { Lottery + Assets }\end{array}$ & $\begin{array}{c}\text { (3) } \\
\text { Lottery Only }\end{array}$ & $\begin{array}{c}\text { (4) } \\
\text { Lottery + Assets }\end{array}$ \\
\hline \multicolumn{5}{|l|}{ Panel A: Anthropometric Outcomes } \\
\hline \multirow[t]{4}{*}{ Stunted } & -0.028 & -0.024 & $-0.089 * *$ & $-0.107 * * *$ \\
\hline & $(0.035)$ & $(0.031)$ & $(0.039)$ & $(0.037)$ \\
\hline & 7,707 & 7,707 & 5,211 & 5,211 \\
\hline & 0.513 & 0.513 & 0.390 & 0.390 \\
\hline \multirow[t]{4}{*}{ Severely stunted } & -0.023 & -0.014 & $-0.100 * * *$ & $-0.112 * * *$ \\
\hline & $(0.034)$ & $(0.031)$ & $(0.029)$ & $(0.030)$ \\
\hline & 7,707 & 7,707 & 5,211 & 5,211 \\
\hline & 0.306 & 0.306 & 0.180 & 0.180 \\
\hline \multirow[t]{4}{*}{ Malnourished } & -0.008 & -0.024 & -0.009 & -0.052 \\
\hline & $(0.028)$ & $(0.027)$ & $(0.033)$ & $(0.032)$ \\
\hline & 7,860 & 7,860 & 5,231 & 5,231 \\
\hline & 0.332 & 0.332 & 0.274 & 0.274 \\
\hline \multirow[t]{4}{*}{ Severely malnourished } & 0.004 & -0.010 & -0.003 & -0.023 \\
\hline & $(0.018)$ & $(0.018)$ & $(0.020)$ & $(0.023)$ \\
\hline & 7,860 & 7,860 & 5,231 & 5,231 \\
\hline & 0.097 & 0.097 & 0.068 & 0.068 \\
\hline \multicolumn{5}{|l|}{ Panel B: Acute Child Morbidity } \\
\hline \multirow[t]{4}{*}{ Diarrhea last month } & 0.041 & $0.051 * *$ & -0.013 & -0.009 \\
\hline & $(0.029)$ & $(0.026)$ & $(0.036)$ & $(0.032)$ \\
\hline & 7,931 & 7,931 & 4,369 & 4,369 \\
\hline & 0.199 & 0.199 & 0.221 & 0.221 \\
\hline \multirow[t]{4}{*}{ Fever or cough last month } & 0.050 & 0.048 & 0.012 & 0.009 \\
\hline & $(0.039)$ & $(0.035)$ & $(0.047)$ & $(0.042)$ \\
\hline & 7,933 & 7,933 & 4,376 & 4,376 \\
\hline & 0.545 & 0.545 & 0.535 & 0.535 \\
\hline \multicolumn{5}{|l|}{ Panel C: Maternal Knowledge Outcomes } \\
\hline \multirow[t]{4}{*}{ Knows birth weight } & $0.105^{* *}$ & $0.148 * * *$ & $0.154 * * *$ & $0.134 * *$ \\
\hline & $(0.049)$ & $(0.048)$ & $(0.052)$ & $(0.054)$ \\
\hline & 2,064 & 2,064 & 2,129 & 2,129 \\
\hline & 0.742 & 0.742 & 0.838 & 0.838 \\
\hline \multirow[t]{4}{*}{ Mother's composite knowledge \% (of 5) } & 0.018 & 0.016 & 0.020 & 0.018 \\
\hline & $(0.017)$ & $(0.015)$ & $(0.018)$ & $(0.015)$ \\
\hline & 6,803 & 6,803 & 6,093 & 6,093 \\
\hline & 0.547 & 0.547 & 0.580 & 0.580 \\
\hline
\end{tabular}

Note: "Stunted" indicates children with height-for-age $z$-scores below -2 , and "severely stunted" indicates children with height-for-age $z$-scores below -3. "Malnourished" indicates children with weight-for-age $z$-scores below -2, and "severely malnourished" indicates children with weight-for-age $z$-scores below -3. "Mother's composite knowledge $\% "$ refers to the number of correct answers to five feeding and childrearing-related questions converted to a percent score. Baseline controls and fixed effects are as listed in Table 1. Regressions in Panels A and B also include agebin controls for each month of age up to 1 year, and for each quarter-year of age between 1 and 5 years. Adjusting $p$-values to control the family-wise error rate within each panel, as described by Romano and Wolf (2005; 2016), all significant effects remain significant. Standard errors, clustered by sub-district, are shown in parentheses.

$* p<0.1 * * p<0.05 * * * p<0.01$. 
Table 4: IV Effect of PKH on Incentivized Education Indicators

\begin{tabular}{|c|c|c|c|c|}
\hline \multirow[b]{2}{*}{ Outcome: } & \multicolumn{2}{|c|}{ 2-Year } & \multicolumn{2}{|c|}{ 6-Year } \\
\hline & $\begin{array}{c}\text { (1) } \\
\text { Lottery Only }\end{array}$ & $\begin{array}{c}(2) \\
\text { Lottery + Assets }\end{array}$ & $\begin{array}{c}\text { (3) } \\
\text { Lottery Only }\end{array}$ & $\begin{array}{c}\text { (4) } \\
\text { Lottery + Assets }\end{array}$ \\
\hline \multicolumn{5}{|l|}{ Panel A: Enrollment for Ages 7-15 } \\
\hline Enrolled in school (any level) & $\begin{array}{c}0.064 * * * \\
(0.013) \\
17,525 \\
0.903\end{array}$ & $\begin{array}{c}0.068 * * * \\
(0.013) \\
17,525 \\
0.903\end{array}$ & $\begin{array}{c}0.040 * * * \\
(0.012) \\
17,720 \\
0.924\end{array}$ & $\begin{array}{c}0.039 * * * \\
(0.011) \\
17,720 \\
0.924\end{array}$ \\
\hline$>85 \%$ attendance last two weeks & $\begin{array}{c}0.070 * * * \\
(0.016) \\
17,437 \\
0.830\end{array}$ & $\begin{array}{c}0.080 * * * \\
(0.015) \\
17,437 \\
0.830\end{array}$ & $\begin{array}{c}0.057 * * * \\
(0.017) \\
17,710 \\
0.856\end{array}$ & $\begin{array}{c}0.058 * * * \\
(0.015) \\
17,710 \\
0.856\end{array}$ \\
\hline \multicolumn{5}{|l|}{ Panel B: Outcomes for Ages 7-12 } \\
\hline Enrolled in school (any level) & $\begin{array}{c}0.037 * * * \\
(0.009) \\
11,957 \\
0.960\end{array}$ & $\begin{array}{c}0.044 * * * \\
(0.009) \\
11,957 \\
0.960\end{array}$ & $\begin{array}{c}0.012 \\
(0.008) \\
11,963 \\
0.972\end{array}$ & $\begin{array}{c}0.015^{*} * \\
(0.007) \\
11,963 \\
0.972\end{array}$ \\
\hline Enrolled in primary school & $\begin{array}{c}0.012 \\
(0.014) \\
11,957 \\
0.887\end{array}$ & $\begin{array}{c}0.024 * * \\
(0.012) \\
11,957 \\
0.887\end{array}$ & $\begin{array}{c}0.011 \\
(0.016) \\
11,963 \\
0.879\end{array}$ & $\begin{array}{c}0.017 \\
(0.014) \\
11,963 \\
0.879\end{array}$ \\
\hline$>85 \%$ attendance last two weeks & $\begin{array}{c}0.041 * * \\
(0.016) \\
11,893 \\
0.881\end{array}$ & $\begin{array}{c}0.054 * * * \\
(0.015) \\
11,893 \\
0.881\end{array}$ & $\begin{array}{c}0.034 * * \\
(0.017) \\
11,957 \\
0.895\end{array}$ & $\begin{array}{c}0.039 * * * \\
(0.015) \\
11,957 \\
0.895\end{array}$ \\
\hline Panel C: Primary-Secondary Transition, & & & & \\
\hline Transitioned from primary to secondary & $\begin{array}{c}0.095 * * * \\
(0.025) \\
5,538 \\
0.891\end{array}$ & $\begin{array}{c}0.087 * * * \\
(0.024) \\
5,538 \\
0.891\end{array}$ & $\begin{array}{c}0.029 \\
(0.018) \\
6,049 \\
0.941\end{array}$ & $\begin{array}{c}0.029 * \\
(0.017) \\
6,049 \\
0.941\end{array}$ \\
\hline Panel D: Outcomes for Ages 13-15 & & & & \\
\hline Enrolled in school (any level) & $\begin{array}{c}0.121 * * * \\
(0.032) \\
5,568 \\
0.783\end{array}$ & $\begin{array}{c}0.125^{* * *} * \\
(0.030) \\
5,568 \\
0.783\end{array}$ & $\begin{array}{c}0.090 * * * \\
(0.027) \\
5,757 \\
0.826\end{array}$ & $\begin{array}{c}0.081 * * * \\
(0.025) \\
5,757 \\
0.826\end{array}$ \\
\hline Enrolled in secondary school & $\begin{array}{c}0.075 * * \\
(0.037) \\
5,568 \\
0.585\end{array}$ & $\begin{array}{c}0.090 * * * \\
(0.034) \\
5,568 \\
0.585\end{array}$ & $\begin{array}{c}0.054 \\
(0.034) \\
5,757 \\
0.609\end{array}$ & $\begin{array}{c}0.058 * \\
(0.031) \\
5,757 \\
0.609\end{array}$ \\
\hline$>85 \%$ attendance last two weeks & $\begin{array}{c}0.132 * * * \\
(0.033) \\
5,544 \\
0.723\end{array}$ & $\begin{array}{c}0.141 * * * \\
(0.030) \\
5,544 \\
0.723\end{array}$ & $\begin{array}{c}0.099 * * * \\
(0.029) \\
5,753 \\
0.777\end{array}$ & $\begin{array}{c}0.087 * * * \\
(0.027) \\
5,753 \\
0.777\end{array}$ \\
\hline
\end{tabular}

Note: This table explores school enrollment and attendance outcomes. "Transitioned from primary to secondary" indicates children who, conditional on having completed primary school, continued on to secondary school. Baseline controls and fixed effects are as listed in Table 1. Adjusting $p$-values to control the family-wise error rate within each panel, as described by Romano and Wolf $(2005 ; 2016)$, all significant effects remain significant. Standard errors, clustered by sub-district, are shown in parentheses.

$* p<0.1 * * p<0.05 * * * p<0.01$. 
Table 5: IV Effect of PKH on Child Labor

\begin{tabular}{|c|c|c|c|c|}
\hline \multirow[b]{2}{*}{ Outcome: } & \multicolumn{2}{|c|}{ 2-Year } & \multicolumn{2}{|c|}{ 6-Year } \\
\hline & $\begin{array}{c}\text { (1) } \\
\text { Lottery Only }\end{array}$ & $\begin{array}{c}\text { (2) } \\
\text { Lottery + Assets }\end{array}$ & $\begin{array}{c}\text { (3) } \\
\text { Lottery Only }\end{array}$ & $\begin{array}{c}\text { (4) } \\
\text { Lottery + Assets }\end{array}$ \\
\hline \multicolumn{5}{|l|}{ Panel A: Outcomes for Ages 7-12 } \\
\hline Worked for wage last month & $\begin{array}{c}-0.015^{*} \\
(0.008) \\
11,958 \\
0.022\end{array}$ & $\begin{array}{c}-0.011 \\
(0.007) \\
11,958 \\
0.022\end{array}$ & $\begin{array}{c}-0.003 \\
(0.007) \\
11,963 \\
0.016\end{array}$ & $\begin{array}{c}-0.003 \\
(0.006) \\
11,963 \\
0.016\end{array}$ \\
\hline Worked 20+ hours for wage last month & $\begin{array}{c}-0.001 \\
(0.004) \\
11,943 \\
0.006\end{array}$ & $\begin{array}{c}-0.001 \\
(0.004) \\
11,943 \\
0.006\end{array}$ & $\begin{array}{c}-0.001 \\
(0.003) \\
11,947 \\
0.004\end{array}$ & $\begin{array}{c}-0.000 \\
(0.003) \\
11,947 \\
0.004\end{array}$ \\
\hline \multicolumn{5}{|l|}{ Panel B: Outcomes for Ages 13-15 } \\
\hline Worked for wage last month & $\begin{array}{c}-0.041 * * \\
(0.021) \\
5,569 \\
0.098\end{array}$ & $\begin{array}{c}-0.024 \\
(0.019) \\
5,569 \\
0.098\end{array}$ & $\begin{array}{c}-0.044 * * \\
(0.020) \\
5,757 \\
0.092\end{array}$ & $\begin{array}{c}-0.031 \\
(0.019) \\
5,757 \\
0.092\end{array}$ \\
\hline Worked 20+ hours for wage last month & $\begin{array}{c}-0.046 * * * \\
(0.016) \\
5,515 \\
0.061\end{array}$ & $\begin{array}{c}-0.036 * * * \\
(0.014) \\
5,515 \\
0.061\end{array}$ & $\begin{array}{c}-0.030^{*} \\
(0.017) \\
5,708 \\
0.055\end{array}$ & $\begin{array}{c}-0.024 \\
(0.015) \\
5,708 \\
0.055\end{array}$ \\
\hline
\end{tabular}

Note: This table examines the effects of PKH on child labor outcomes based on survey responses. Outcomes are dummy variables indicating if children performed any work for wage (or 20+ hours of wage work) in the past month. This definition does not include household labor. Baseline controls and fixed effects are as listed in Table 1. Adjusting $p$-values to control the family-wise error rate within each panel, as described by Romano and Wolf (2005; 2016), all significant effects remain significant. Standard errors, clustered by sub-district, are shown in parentheses.

$* p<0.1 * * p<0.05 * * * p<0.01$. 
Table 6: Medium-Run IV Impact of PKH

\begin{tabular}{|c|c|c|c|c|}
\hline \multirow[b]{2}{*}{ Outcome: } & \multicolumn{2}{|c|}{ 2-Year } & \multicolumn{2}{|c|}{ 6-Year } \\
\hline & $\begin{array}{c}\text { (1) } \\
\text { Lottery Only }\end{array}$ & $\begin{array}{c}(2) \\
\text { Lottery + Assets }\end{array}$ & $\begin{array}{c}\text { (3) } \\
\text { Lottery Only }\end{array}$ & $\begin{array}{c}(4) \\
\text { Lottery + Assets }\end{array}$ \\
\hline \multicolumn{5}{|l|}{ Panel A: School Enrollment/Completion Outcomes } \\
\hline \multirow[t]{4}{*}{ Enrolled in school (Ages 15-17) } & 0.069 & 0.066 & $0.105^{* *}$ & $0.097 * *$ \\
\hline & $(0.047)$ & $(0.044)$ & $(0.045)$ & $(0.041)$ \\
\hline & 4,211 & 4,211 & 4,957 & 4,957 \\
\hline & 0.536 & 0.536 & 0.616 & 0.616 \\
\hline \multirow[t]{4}{*}{ Enrolled in high school (Ages 15-17) } & 0.016 & 0.023 & $0.074 *$ & 0.056 \\
\hline & $(0.039)$ & $(0.033)$ & $(0.041)$ & $(0.037)$ \\
\hline & 4,212 & 4,212 & 4,957 & 4,957 \\
\hline & 0.301 & 0.301 & 0.393 & 0.393 \\
\hline \multirow[t]{4}{*}{ Completed high school (Ages 18-21) } & & & $0.074 *$ & 0.040 \\
\hline & & & $(0.041)$ & $(0.034)$ \\
\hline & & & 4,263 & 4,263 \\
\hline & & & 0.258 & 0.258 \\
\hline \multicolumn{5}{|l|}{ Panel B: Labor Outcomes (Ages 16-21) } \\
\hline \multirow[t]{4}{*}{ Worked for wage last month (Ages 16-17) } & -0.068 & -0.057 & 0.032 & 0.024 \\
\hline & $(0.053)$ & $(0.050)$ & $(0.041)$ & $(0.038)$ \\
\hline & 2,570 & 2,570 & 3,211 & 3,211 \\
\hline & 0.258 & 0.258 & 0.221 & 0.221 \\
\hline \multirow[t]{4}{*}{ Worked 20+ hours for wage last month (Ages 16-17) } & -0.063 & -0.059 & 0.004 & -0.012 \\
\hline & $(0.049)$ & $(0.044)$ & $(0.038)$ & $(0.036)$ \\
\hline & 2,517 & 2,517 & 3,152 & 3,152 \\
\hline & 0.188 & 0.188 & 0.172 & 0.172 \\
\hline \multirow[t]{4}{*}{ Worked for wage last month (Ages 18-21) } & & & -0.059 & -0.035 \\
\hline & & & $(0.048)$ & $(0.040)$ \\
\hline & & & 4,263 & 4,263 \\
\hline & & & 0.478 & 0.478 \\
\hline \multirow[t]{4}{*}{ Worked 20+ hours for wage last month (Ages 18-21) } & & & -0.043 & -0.019 \\
\hline & & & $(0.047)$ & $(0.039)$ \\
\hline & & & 4,139 & 4,139 \\
\hline & & & 0.423 & 0.423 \\
\hline \multicolumn{5}{|l|}{ Panel C: Marriage Outcomes (Ages 16-21) } \\
\hline \multirow[t]{4}{*}{ Married (Ages 16-17) } & -0.026 & -0.024 & -0.012 & -0.007 \\
\hline & $(0.020)$ & $(0.019)$ & $(0.025)$ & $(0.024)$ \\
\hline & 2,570 & 2,570 & 3,032 & 3,032 \\
\hline & 0.041 & 0.041 & 0.056 & 0.056 \\
\hline \multirow[t]{4}{*}{ Married (Ages 18-21) } & & & -0.017 & -0.018 \\
\hline & & & $(0.036)$ & $(0.032)$ \\
\hline & & & 4,123 & 4,123 \\
\hline & & & 0.186 & 0.186 \\
\hline
\end{tabular}

Note: This table explores schooling, labor, and marriage outcomes for children who were between the ages of 6-15 (i.e., schooling age) during the baseline survey and initial program rollout. Outcomes for ages 18-21 are omitted from Columns 1 and 2 (2-year follow-up) because virtually none of these children had turned 18 by the time of the follow-up survey. Baseline controls and fixed effects are as listed in Table 1. Adjusting $p$-values to control the family-wise error rate within each panel, as described by Romano and Wolf $(2005 ; 2016)$, all significant effects remain significant. Standard errors, clustered by sub-district, are shown in parentheses.

$* p<0.1 * * p<0.05 * * * p<0.01$. 
Table 7: IV Effect of PKH on Household Economic Outcomes

\begin{tabular}{|c|c|c|c|c|}
\hline \multirow[b]{2}{*}{ Outcome: } & \multicolumn{2}{|c|}{ 2-Year } & \multicolumn{2}{|c|}{ 6-Year } \\
\hline & $\begin{array}{c}\text { (1) } \\
\text { Lottery Only }\end{array}$ & $\begin{array}{c}(2) \\
\text { Lottery + Assets }\end{array}$ & $\begin{array}{c}\text { (3) } \\
\text { Lottery Only }\end{array}$ & $\begin{array}{c}\text { (4) } \\
\text { Lottery + Assets }\end{array}$ \\
\hline \multicolumn{5}{|l|}{ Panel A: Household Expenditure Outcomes } \\
\hline \multirow[t]{4}{*}{ Log per-capita expenditure } & -0.006 & 0.006 & 0.037 & 0.031 \\
\hline & $(0.035)$ & $(0.032)$ & $(0.037)$ & $(0.032)$ \\
\hline & 14,609 & 14,609 & 15,510 & 15,510 \\
\hline & 12.353 & 12.353 & 12.898 & 12.898 \\
\hline \multirow[t]{4}{*}{ Log per-capita food expenditure } & -0.000 & 0.006 & 0.028 & 0.023 \\
\hline & $(0.036)$ & $(0.032)$ & $(0.038)$ & $(0.032)$ \\
\hline & 14,610 & 14,610 & 15,509 & 15,509 \\
\hline & 11.947 & 11.947 & 12.439 & 12.439 \\
\hline \multirow[t]{4}{*}{ Log per-capita alcohol + tobacco expenditure } & 0.030 & -0.007 & 0.169 & 0.170 \\
\hline & $(0.230)$ & $(0.200)$ & $(0.248)$ & $(0.217)$ \\
\hline & 14,605 & 14,605 & 15,511 & 15,511 \\
\hline & 7.477 & 7.477 & 7.967 & 7.967 \\
\hline \multirow[t]{4}{*}{ Log per-capita health + education expenditure } & -0.033 & -0.015 & 0.126 & 0.164 \\
\hline & $(0.206)$ & $(0.198)$ & $(0.284)$ & $(0.275)$ \\
\hline & 14,610 & 14,610 & 15,510 & 15,510 \\
\hline & 8.535 & 8.535 & 8.846 & 8.846 \\
\hline \multirow[t]{4}{*}{ Log per-capita milk + eggs expenditure } & 0.344 & $0.474 * *$ & 0.187 & 0.273 \\
\hline & $(0.232)$ & $(0.231)$ & $(0.246)$ & $(0.242)$ \\
\hline & 14,609 & 14,609 & 15,512 & 15,512 \\
\hline & 6.340 & 6.340 & 7.258 & 7.258 \\
\hline \multicolumn{5}{|l|}{ Panel B: Household Land + Livestock Investment } \\
\hline \multirow[t]{4}{*}{ Owns any land } & -0.011 & -0.008 & 0.007 & 0.012 \\
\hline & $(0.017)$ & $(0.014)$ & $(0.021)$ & $(0.017)$ \\
\hline & 14,757 & 14,757 & 15,667 & 15,667 \\
\hline & 0.915 & 0.915 & 0.909 & 0.909 \\
\hline \multirow[t]{4}{*}{ Head of household employed } & 0.001 & -0.002 & -0.004 & 0.000 \\
\hline & $(0.014)$ & $(0.011)$ & $(0.011)$ & $(0.010)$ \\
\hline & 13,965 & 13,965 & 14,817 & 14,817 \\
\hline & 0.940 & 0.940 & 0.943 & 0.943 \\
\hline \multirow[t]{4}{*}{ Total number of livestock owned } & -0.529 & -0.334 & -1.203 & 0.131 \\
\hline & $(0.468)$ & $(0.424)$ & $(1.575)$ & $(0.975)$ \\
\hline & 14,757 & 14,757 & 15,667 & 15,667 \\
\hline & 3.883 & 3.883 & 4.753 & 4.753 \\
\hline
\end{tabular}

Note: This table reports effects on various household-level consumption and investment outcomes. In Panel A, households above the 99th percentile for each category of expenditure are dropped from the regressions for that specific category. Adjusting $p$-values to control the family-wise error rate within each panel, as described by Romano and Wolf (2005; 2016), the effect on milk and egg consumption in Column 2 is significant only at the $10 \%$ level. Baseline controls and fixed effects are as listed in Table 1. Standard errors, clustered by sub-district, are shown in parentheses.

$* p<0.1 * * p<0.05 * * * p<0.01$. 
Appendix Figure 1: Conditions for PKH Receipt

\begin{tabular}{|c|c|}
\hline Household Category & Conditions \\
\hline Households with pregnant or lactating women & $\begin{array}{l}\text { - Complete } 4 \text { pre-natal visits and take iron tablets during pregnancy } \\
\text { - Give birth assisted by a trained professional } \\
\text { - Complete two post-natal visits (lactating mothers) }\end{array}$ \\
\hline Households with children aged 0-6 years & $\begin{array}{l}\text { - Ensure children receive all immunizations and take Vitamin A twice a } \\
\text { year } \\
\text { - Take children for growth monitoring check-ups (monthly for infants } \\
\text { up to } 11 \text { months old, quarterly for children 1-6 years old) }\end{array}$ \\
\hline Households with children aged 6-15 years & $\begin{array}{l}\text { - Enroll children in primary/secondary school and ensure minimum } 85 \\
\text { percent attendance }\end{array}$ \\
\hline $\begin{array}{l}\text { Households with children aged } 16-18 \text { who have not yet } \\
\text { completed } 9 \text { years of schooling }\end{array}$ & - Enroll children in education program to complete 9 years of schooling \\
\hline
\end{tabular}

Note: Adapted from Alatas (2011). 
Appendix Figure 2: Number of Sub-Districts by Province and Treatment Assignment

\begin{tabular}{lccc}
\hline Province & Control & Treatment & Total \\
\hline DKI Jakarta & 1 & 1 & 2 \\
West Java & 41 & 41 & 82 \\
East Java & 87 & 87 & 174 \\
East Nusa Tenggara & 26 & 26 & 52 \\
North Sulawesi & 22 & 22 & 44 \\
Gorontalo & 3 & 3 & 6 \\
\hline Total & 180 & 180 & 360 \\
\hline
\end{tabular}

Note: This table lists the number of sample sub-districts (kecamatan) by province and baseline treatment assignment. "DKI Jakarta" is shorthand for Special Capital City District of Jakarta. 
Appendix Figure 3: Experiment Timeline

\begin{tabular}{|c|c|c|c|c|c|c|c|c|c|}
\hline & \multicolumn{2}{|c|}{$\begin{array}{l}\text { June - August 2007: } \\
\text { Baseline Survey }\end{array}$} & \multicolumn{3}{|c|}{$\begin{array}{l}\text { October - December 2009: } \\
\text { Follow-Up (Midline) Survey }\end{array}$} & & \multicolumn{3}{|c|}{$\begin{array}{l}\text { September - November 2013: } \\
\text { Follow-Up (Endline) Survey }\end{array}$} \\
\hline 2006 & 2007 & $\begin{array}{c}1 \\
2008\end{array}$ & $\begin{array}{c}1 \\
2009\end{array}$ & 7 & 1 & 1 & 1 & 2014 & 2015 \\
\hline
\end{tabular}

Late 2007: PKH Pilot Implemented 
Appendix Figure 4: Actual Sub-District Implementation Status, by Baseline Treatment Assignment

\begin{tabular}{lcc}
\hline & \multicolumn{2}{c}{ Baseline Randomization } \\
\cline { 2 - 3 } & Control $(n=180)$ & Treatment $(n=180)$ \\
\hline Treated 2-Year & 39 & 178 \\
Treated 6-Year & $(21.7 \%)$ & $(98.9 \%)$ \\
& 70 & 179 \\
& $(38.9 \%)$ & $(99.4 \%)$ \\
\hline
\end{tabular}

Note: For each baseline treatment assignment, this table lists the number and percentage of the 180 sub-districts that had been treated by the time of each follow-up survey. 

Appendix Figure 5: Treatment Effect on Stunting Outcomes, by Child's Age (6-Year Follow-Up)

\section{Panel A: Effect on Stunting}
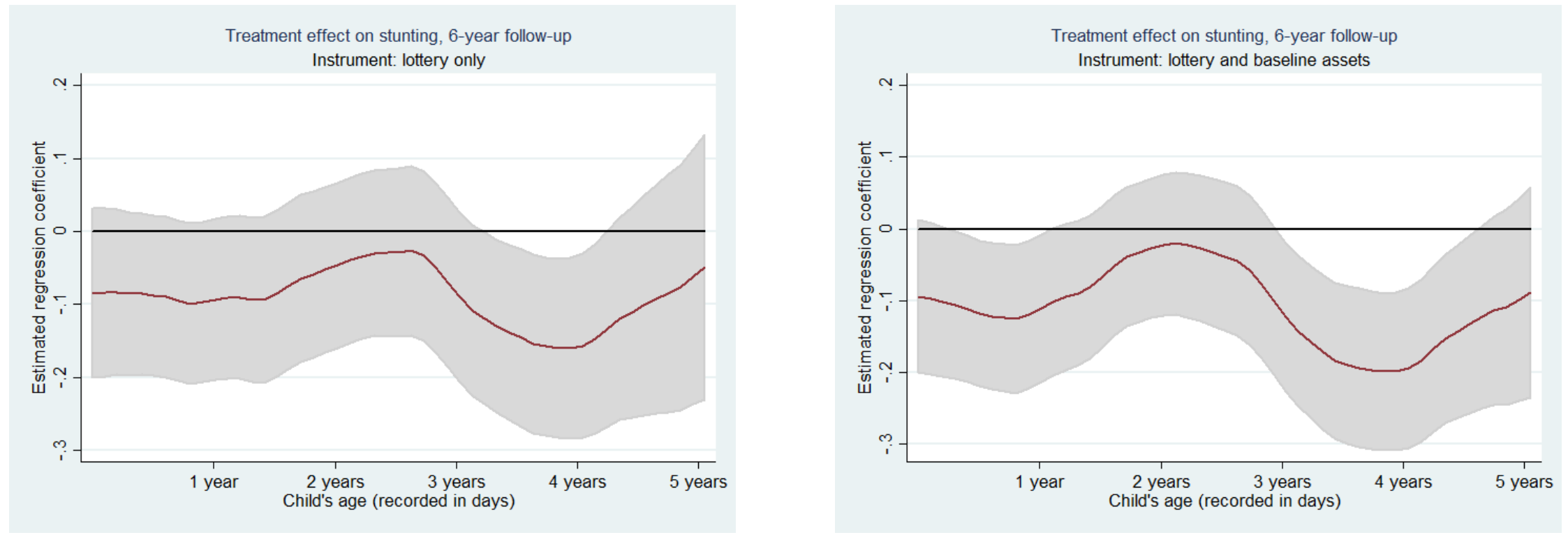

Panel B: Effect on Severe Stunting
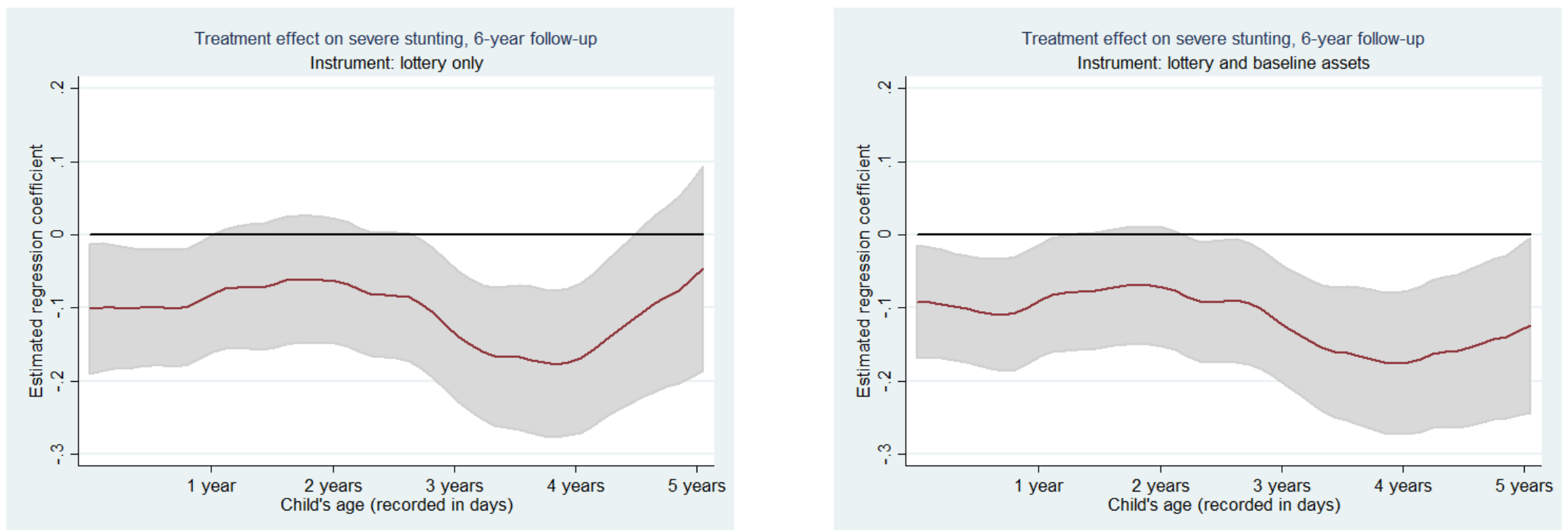

Note: In the above graphs, we plot the effect of PKH receipt on stunting and severe stunting by children's age (recorded in days) in the six-year follow-up survey. At each of 50 equally spaced cutoff points along the $x$-axis, we estimate the IV regression coefficient and apply a triangular kernel smoother with bandwidth equal to $1 / 4$ of the length of the $x$-axis. Red lines indicate point estimates and grey bands indicate $95 \%$ confidence intervals. 
Appendix Table 1: Household Sample Size, by Baseline Treatment Assignment

\begin{tabular}{lcccccc}
\hline & $\begin{array}{c}\text { Control } \\
\text { Households }\end{array}$ & \% of Baseline & $\begin{array}{c}\text { Treatment } \\
\text { Households }\end{array}$ & \% of Baseline & $\begin{array}{c}\text { Total } \\
\text { Households }\end{array}$ & \% of Baseline \\
\hline Baseline & 7,131 & 100 & 7,195 & 100 & 14,326 & 100 \\
2-Year & 6,947 & 97.4 & 7,024 & 97.6 & 13,971 & 97.5 \\
6-Year & 6,768 & 94.9 & 6,851 & 95.2 & 13,619 & 95.1 \\
\hline
\end{tabular}

Note: This table lists the number of households surveyed at baseline and in each follow-up round. For the purpose of calculating attrition of households surveyed at baseline, we exclude split households from this tabulation, but include them in all other analyses. 
Appendix Table 2: Attrition of Child Survey Respondents from Baseline

\begin{tabular}{|c|c|c|c|c|}
\hline \multirow[b]{3}{*}{ Outcome: } & \multicolumn{2}{|c|}{ Full Sample } & \multirow{3}{*}{ 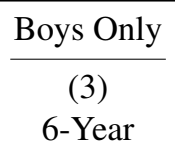 } & \multirow{3}{*}{$\begin{array}{c}\text { Girls Only } \\
\text { 6-Year } \\
\text { 6-Yea }\end{array}$} \\
\hline & (1) & (2) & & \\
\hline & 2-Year & 6-Year & & \\
\hline Lost to Follow-Up & $\begin{array}{l}-0.005 \\
(0.007)\end{array}$ & $\begin{array}{c}-0.011 \\
(0.010)\end{array}$ & $\begin{array}{c}-0.011 \\
(0.011)\end{array}$ & $\begin{array}{c}-0.012 \\
(0.012)\end{array}$ \\
\hline Observations & 18947 & 18947 & 9853 & 9094 \\
\hline Control Mean & 0.102 & 0.276 & 0.257 & 0.297 \\
\hline
\end{tabular}

Note: This table reports attrition of respondents who were ages 6-15 at the time of the baseline survey. Outcome is a dummy variable indicating whether the child attrited by the 2-year or 6-year follow-up survey, respectively. Includes district (kabupaten) fixed effects. Standard errors, clustered by sub-district, are shown in parentheses.

$* p<0.1 * * p<0.05 * * * p<0.01$. 
Appendix Table 3: Attrition of Child Survey Respondents, by Baseline Age

\begin{tabular}{|c|c|c|c|c|}
\hline \multirow[b]{2}{*}{ Outcome: } & \multicolumn{2}{|c|}{ Full Sample } & \multirow{2}{*}{$\begin{array}{c}\text { Boys Only } \\
\text { 6-Year }\end{array}$} & \multirow{2}{*}{$\begin{array}{c}\text { Girls Only } \\
\text { (4) } \\
\text { 6-Year }\end{array}$} \\
\hline & $\begin{array}{c}(1) \\
\text { 2-Year }\end{array}$ & $\begin{array}{c}(2) \\
\text { 6-Year }\end{array}$ & & \\
\hline Lost to Follow-Up (Age 6 at Baseline) & $\begin{array}{c}-0.004 \\
(0.011) \\
1,860 \\
0.050\end{array}$ & $\begin{array}{c}-0.015 \\
(0.016) \\
1,860 \\
0.125\end{array}$ & $\begin{array}{c}-0.006 \\
(0.023) \\
998 \\
0.118\end{array}$ & $\begin{array}{c}-0.025 \\
(0.022) \\
862 \\
0.132\end{array}$ \\
\hline Lost to Follow-Up (Age 7 at Baseline) & $\begin{array}{c}0.003 \\
(0.010) \\
2,042 \\
0.044\end{array}$ & $\begin{array}{c}0.012 \\
(0.017) \\
2,042 \\
0.137\end{array}$ & $\begin{array}{c}0.050 * * \\
(0.022) \\
1,019 \\
0.107\end{array}$ & $\begin{array}{c}-0.028 \\
(0.025) \\
1,023 \\
0.167\end{array}$ \\
\hline Lost to Follow-Up (Age 8 at Baseline) & $\begin{array}{c}0.001 \\
(0.011) \\
1,805 \\
0.045\end{array}$ & $\begin{array}{c}-0.027^{*} \\
(0.016) \\
1,805 \\
0.162\end{array}$ & $\begin{array}{c}-0.042 * \\
(0.024) \\
956 \\
0.164\end{array}$ & $\begin{array}{c}-0.018 \\
(0.024) \\
849 \\
0.160\end{array}$ \\
\hline Lost to Follow-Up (Age 9 at Baseline) & $\begin{array}{c}-0.001 \\
(0.012) \\
1,881 \\
0.058\end{array}$ & $\begin{array}{c}-0.001 \\
(0.021) \\
1,881 \\
0.226\end{array}$ & $\begin{array}{c}-0.014 \\
(0.028) \\
989 \\
0.231\end{array}$ & $\begin{array}{c}0.010 \\
(0.028) \\
892 \\
0.219\end{array}$ \\
\hline Lost to Follow-Up (Age 10 at Baseline) & $\begin{array}{c}-0.008 \\
(0.013) \\
1,941 \\
0.082\end{array}$ & $\begin{array}{c}-0.022 \\
(0.022) \\
1,941 \\
0.269\end{array}$ & $\begin{array}{c}-0.042 \\
(0.028) \\
971 \\
0.240\end{array}$ & $\begin{array}{c}-0.002 \\
(0.030) \\
970 \\
0.298\end{array}$ \\
\hline Lost to Follow-Up (Age 11 at Baseline) & $\begin{array}{c}0.005 \\
(0.015) \\
1,946 \\
0.090\end{array}$ & $\begin{array}{c}0.013 \\
(0.021) \\
1,946 \\
0.279\end{array}$ & $\begin{array}{c}0.020 \\
(0.027) \\
997 \\
0.254\end{array}$ & $\begin{array}{c}0.029 \\
(0.030) \\
949 \\
0.303\end{array}$ \\
\hline Lost to Follow-Up (Age 12 at Baseline) & $\begin{array}{c}-0.021 \\
(0.015) \\
1,923 \\
0.123\end{array}$ & $\begin{array}{c}-0.023 \\
(0.021) \\
1,923 \\
0.365\end{array}$ & $\begin{array}{c}-0.021 \\
(0.029) \\
998 \\
0.351\end{array}$ & $\begin{array}{c}-0.026 \\
(0.031) \\
925 \\
0.382\end{array}$ \\
\hline Lost to Follow-Up (Age 13 at Baseline) & $\begin{array}{c}-0.027 \\
(0.020) \\
1,717 \\
0.181\end{array}$ & $\begin{array}{c}-0.007 \\
(0.025) \\
1,717 \\
0.422\end{array}$ & $\begin{array}{c}0.023 \\
(0.036) \\
898 \\
0.389\end{array}$ & $\begin{array}{c}-0.045 \\
(0.035) \\
819 \\
0.458\end{array}$ \\
\hline Lost to Follow-Up (Age 14 at Baseline) & $\begin{array}{c}-0.012 \\
(0.020) \\
1,874 \\
0.206\end{array}$ & $\begin{array}{c}-0.045^{*} \\
(0.024) \\
1,874 \\
0.455\end{array}$ & $\begin{array}{c}-0.049 \\
(0.032) \\
949 \\
0.415\end{array}$ & $\begin{array}{c}-0.048 \\
(0.034) \\
925 \\
0.499\end{array}$ \\
\hline Lost to Follow-Up (Age 15 at Baseline) & $\begin{array}{c}-0.011 \\
(0.032) \\
828 \\
0.226\end{array}$ & $\begin{array}{c}0.000 \\
(0.037) \\
828 \\
0.445\end{array}$ & $\begin{array}{c}0.040 \\
(0.049) \\
449 \\
0.389\end{array}$ & $\begin{array}{c}-0.037 \\
(0.055) \\
379 \\
0.516\end{array}$ \\
\hline
\end{tabular}

Note: This table reports age-specific attrition of respondents who were ages 6-15 at the time of the baseline survey. Outcome is a dummy variable indicating whether the child attrited by the 2-year or 6-year follow-up survey, respectively. Includes district (kabupaten) fixed effects. Standard errors, clustered by sub-district, are shown in parentheses.

$* p<0.1 * * p<0.05 * * * p<0.01$. 
Appendix Table 4a: Child Attrition Outcomes, 6-Year Follow-Up

\begin{tabular}{lccccc}
\hline Outcome: & Overall & Control & Treatment & $\begin{array}{c}\text { Control - Treatment } \\
p \text {-value }\end{array}$ & $\begin{array}{c}\text { Control - Treatment } \\
p \text {-value (District FE) }\end{array}$ \\
\hline Surveyed & .728 & .724 & .733 & 0.490 & 0.302 \\
Migrated in Last 12 Months, 2-Year & .054 & .054 & .053 & 0.887 & 0.817 \\
Migrated in Last 12 Months, 6-Year & .055 & .055 & .056 & 0.861 & 0.783 \\
Migrated Prior to Last 12 Months, 2-Year & .021 & .023 & .02 & 0.395 & 0.274 \\
Migrated Prior to Last 12 Months, 6-Year & .092 & .094 & .089 & 0.453 & 0.272 \\
Died 2-Year & .002 & .002 & .002 & 0.688 & 0.686 \\
Died 6-Year & .004 & .004 & .003 & 0.155 & 0.125 \\
Still in Household Roster, 2-Year & .001 & .001 & .001 & 0.386 & 0.387 \\
Still in Household Roster, 6-Year & .001 & 0 & .001 & 0.062 & 0.048 \\
Household Attrited & .039 & .04 & .039 & 0.933 & 0.806 \\
Unaccounted For & .002 & .003 & .002 & 0.175 & 0.139 \\
\hline
\end{tabular}

Note: This table reports attrition outcomes for children in the 6-year follow-up survey, disaggregated by baseline treatment status. Children in the baseline survey module $(n=18,947)$ were either tracked and surveyed in the 6-year follow-up ("Surveyed") or attrited from the survey module for one of the reasons listed in the table. Column 4 lists two-sided $p$-values for the difference between control and treatment groups for each outcome, clustered by sub-district.

Appendix Table 4b: Reasons for Child Migration

\begin{tabular}{lccccc}
\hline Outcome: & Overall & Control & Treatment & $\begin{array}{c}\text { Control - Treatment } \\
p \text {-value }\end{array}$ & $\begin{array}{c}\text { Control - Treatment } \\
p \text {-value (District FE) }\end{array}$ \\
\hline Migrated for School & .286 & .292 & .281 & 0.792 & 0.277 \\
Migrated for Work & .494 & .494 & .495 & 0.997 & 0.647 \\
Migrated to Follow Spouse & .083 & .09 & .077 & 0.353 & 0.461 \\
Migrated for Other Reason & .136 & .125 & .147 & 0.222 & 0.096 \\
\hline
\end{tabular}

Note: This table reports reasons for child migration, disaggregated by baseline treatment status, among those who had migrated within 12 months leading up to the 2- and 6-year follow-up surveys. Column 4 lists two-sided $p$-values for the difference between control and treatment groups for each outcome, clustered by sub-district and controlling for whether a child migrated in the 2- or 6-year follow-up. 
Appendix Table 5: Effect of Treatment on Miscarriage, Stillbirth, and Infant Mortality

\begin{tabular}{|c|c|c|c|c|}
\hline \multirow[b]{2}{*}{ Outcome: } & \multicolumn{2}{|c|}{ 2-Year } & \multicolumn{2}{|c|}{ 6-Year } \\
\hline & $\begin{array}{c}\text { (1) } \\
\text { Lottery Only }\end{array}$ & $\begin{array}{c}\text { (2) } \\
\text { Lottery + Assets }\end{array}$ & $\begin{array}{c}\text { (3) } \\
\text { Lottery Only }\end{array}$ & $\begin{array}{c}\text { (4) } \\
\text { Lottery + Assets }\end{array}$ \\
\hline Panel A: Pregnancy Outcomes & & & & \\
\hline Miscarriage or stillbirth in last 24 months & $\begin{array}{c}-0.014 \\
(0.029) \\
2,235 \\
0.079\end{array}$ & $\begin{array}{c}0.001 \\
(0.028) \\
2,235 \\
0.079\end{array}$ & $\begin{array}{c}0.008 \\
(0.031) \\
2,288 \\
0.069\end{array}$ & $\begin{array}{c}0.023 \\
(0.028) \\
2,288 \\
0.069\end{array}$ \\
\hline Panel B: Infant Mortality & & & & \\
\hline Child $0-28$ days died in last 24 months & $\begin{array}{c}-0.020 \\
(0.014) \\
2,000 \\
0.021\end{array}$ & & $\begin{array}{c}0.023 \\
(0.018) \\
1,885 \\
0.017\end{array}$ & \\
\hline Child 1-12 months died in last 24 months & $\begin{array}{c}-0.009 \\
(0.012) \\
2,000 \\
0.015\end{array}$ & & $\begin{array}{c}-0.021 \\
(0.014) \\
1,885 \\
0.016\end{array}$ & \\
\hline
\end{tabular}

Note: This table reports miscarriage, stillbirth, and infant mortality rates among women who had given birth within 24 months prior to each follow-up survey. Baseline controls and fixed effects are as listed in Table 1. Panel B regressions also include month-of-birth controls for 24 months prior to the survey date. We omit child mortality outcomes in Columns 2 and 4 because the sparsity of mortality observations prevents conducting regressions with the "Lottery + Assets" instrument. Standard errors, clustered by sub-district, are shown in parentheses. 
Appendix Table 6: Baseline Balance Check of Randomization

\begin{tabular}{|c|c|c|c|c|c|}
\hline & Observations & Control Mean & Treatment Mean & $\begin{array}{l}\text { Treatment Effect } \\
\text { (No Controls) }\end{array}$ & $\begin{array}{l}\text { Treatment Effect } \\
\text { (District FE) }\end{array}$ \\
\hline \multicolumn{6}{|l|}{ Panel A: Mothers Ages 16-49 } \\
\hline Pre-natal visits & 5,705 & 6.631 & 6.643 & $\begin{array}{c}0.011 \\
(0.214)\end{array}$ & $\begin{array}{c}0.006 \\
(0.182)\end{array}$ \\
\hline $90+$ iron pills during pregnancy & 4,638 & 0.139 & 0.140 & $\begin{array}{c}0.001 \\
(0.016)\end{array}$ & $\begin{array}{c}0.000 \\
(0.014)\end{array}$ \\
\hline Good assisted delivery & 4,669 & 0.627 & 0.642 & $\begin{array}{c}0.015 \\
(0.032)\end{array}$ & $\begin{array}{c}0.016 \\
(0.021)\end{array}$ \\
\hline Post-natal visits & 4,669 & 1.761 & 2.030 & $\begin{array}{c}0.269 \\
(0.192)\end{array}$ & $\begin{array}{c}0.268 \\
(0.170)\end{array}$ \\
\hline \multicolumn{6}{|l|}{ Panel B: Children Ages 0-5 } \\
\hline Immunizations complete for age & 6,088 & 0.339 & 0.346 & $\begin{array}{c}0.008 \\
(0.021)\end{array}$ & $\begin{array}{c}0.010 \\
(0.017)\end{array}$ \\
\hline$\%$ of required immunizations completed & 6,088 & 0.621 & 0.622 & $\begin{array}{c}0.001 \\
(0.020)\end{array}$ & $\begin{array}{c}0.004 \\
(0.016)\end{array}$ \\
\hline Times weighed in last 3 months & 6,152 & 2.058 & 2.111 & $\begin{array}{c}0.054 \\
(0.072)\end{array}$ & $\begin{array}{c}0.046 \\
(0.062)\end{array}$ \\
\hline Times received Vitamin A (Ages 6 mos. - 2 yrs.) & 3,154 & 1.761 & 1.755 & $\begin{array}{l}-0.006 \\
(0.068)\end{array}$ & $\begin{array}{l}-0.015 \\
(0.060)\end{array}$ \\
\hline \multicolumn{6}{|l|}{ Panel C: Children Ages 6-15 } \\
\hline Enrolled in school (Ages 7-12) & 11,538 & 0.926 & 0.928 & $\begin{array}{c}0.002 \\
(0.007)\end{array}$ & $\begin{array}{c}0.001 \\
(0.006)\end{array}$ \\
\hline Enrolled in school (Ages 13-15) & 4,419 & 0.703 & 0.686 & $\begin{array}{l}-0.018 \\
(0.021)\end{array}$ & $\begin{array}{l}-0.023 \\
(0.018)\end{array}$ \\
\hline$\%$ school attendance last 2 weeks (Ages 7-12) & 10,113 & 0.886 & 0.890 & $\begin{array}{c}0.004 \\
(0.010)\end{array}$ & $\begin{array}{c}0.004 \\
(0.009)\end{array}$ \\
\hline$\%$ school attendance last 2 weeks (Ages 13-15) & 3,999 & 0.643 & 0.628 & $\begin{array}{l}-0.016 \\
(0.024)\end{array}$ & $\begin{array}{l}-0.020 \\
(0.021)\end{array}$ \\
\hline$>85 \%$ attendance last 2 weeks (Ages 7-12) & 10,113 & 0.860 & 0.867 & $\begin{array}{c}0.006 \\
(0.012)\end{array}$ & $\begin{array}{c}0.005 \\
(0.011)\end{array}$ \\
\hline$>85 \%$ attendance last 2 weeks (Ages 13-15) & 3,999 & 0.625 & 0.611 & $\begin{array}{l}-0.015 \\
(0.025)\end{array}$ & $\begin{array}{l}-0.019 \\
(0.021)\end{array}$ \\
\hline
\end{tabular}

Note: This table examines baseline differences between control and treatment sub-districts along several key outcome variables. Column 1 reports the number of observations of each outcome in the baseline sample. Columns 2 and 3 report the control and treatment group means, respectively. In Column 4, we report coefficients of OLS regressions on baseline treatment assignment, with no other controls included. In Column 5 , we repeat the regression and add district (kabupaten) fixed effects. Standard errors, clustered by sub-district, are shown in parentheses.

$* p<0.1 * * p<0.05 * * * p<0.01$. 
Appendix Table 7: First-Stage Regressions, Household Level (All Interactions)

\begin{tabular}{|c|c|c|c|c|}
\hline \multirow[b]{2}{*}{ Outcome: Ever Received PKH } & \multicolumn{2}{|c|}{ 2-Year } & \multicolumn{2}{|c|}{ 6-Year } \\
\hline & $\begin{array}{c}\text { (1) } \\
\text { Lottery Only }\end{array}$ & $\begin{array}{c}(2) \\
\text { Lottery + Assets }\end{array}$ & $\begin{array}{c}\text { (3) } \\
\text { Lottery Only }\end{array}$ & $\begin{array}{c}\text { (4) } \\
\text { Lottery + Assets }\end{array}$ \\
\hline Treatment & $\begin{array}{c}0.375 * * * \\
(0.017)\end{array}$ & $\begin{array}{l}0.299 * * * \\
(0.060)\end{array}$ & $\begin{array}{c}0.368 * * * \\
(0.017)\end{array}$ & $\begin{array}{c}0.331 * * * \\
(0.042)\end{array}$ \\
\hline HHH Works in Agriculture $\times$ Lottery & & $\begin{array}{c}0.020 \\
(0.021)\end{array}$ & & $\begin{array}{c}0.017 \\
(0.023)\end{array}$ \\
\hline HHH Works in Services $\times$ Lottery & & $\begin{array}{c}0.011 \\
(0.027)\end{array}$ & & $\begin{array}{c}0.002 \\
(0.027)\end{array}$ \\
\hline HHH Education: SD Incomplete $\times$ Lottery & & $\begin{array}{c}0.410^{* * * *} \\
(0.132)\end{array}$ & & $\begin{array}{c}1.786^{* * *} \\
(0.305)\end{array}$ \\
\hline HHH Education: SD/MI $\times$ Lottery & & $\begin{array}{c}0.419 * * * \\
(0.133)\end{array}$ & & $\begin{array}{c}1.781 * * * \\
(0.302)\end{array}$ \\
\hline HHH Education: SMP/MTs $\times$ Lottery & & $\begin{array}{c}0.409 * * * \\
(0.134)\end{array}$ & & $\begin{array}{c}1.764 * * * \\
(0.302)\end{array}$ \\
\hline HHH Education: SMA/MA $\times$ Lottery & & $\begin{array}{c}0.412 * * * \\
(0.139)\end{array}$ & & $\begin{array}{c}1.782 * * * \\
(0.306)\end{array}$ \\
\hline HHH Education: D1/D2/D3 × Lottery & & $\begin{array}{c}0.082 \\
(0.203)\end{array}$ & & $\begin{array}{c}1.398 * * * \\
(0.370)\end{array}$ \\
\hline HHH Education: D4/S1 × Lottery & & $\begin{array}{c}0.039 \\
(0.177)\end{array}$ & & $\begin{array}{c}1.605 * * * \\
(0.389)\end{array}$ \\
\hline HHH Education: Never Attended School $\times$ Lottery & & $\begin{array}{c}0.388^{* * * *} \\
(0.133)\end{array}$ & & $\begin{array}{c}1.763 * * * \\
(0.303)\end{array}$ \\
\hline HHH Education: Do Not Know $\times$ Lottery & & $\begin{array}{l}0.357^{*} \\
(0.195)\end{array}$ & & $\begin{array}{c}1.779 * * * \\
(0.337)\end{array}$ \\
\hline Roof Type $1 \times$ Lottery & & $\begin{array}{l}-0.195 \\
(0.143)\end{array}$ & & $\begin{array}{l}-0.155 \\
(0.147)\end{array}$ \\
\hline Roof Type $2 \times$ Lottery & & $\begin{array}{l}-0.252^{*} \\
(0.130)\end{array}$ & & $\begin{array}{l}-0.259^{*} \\
(0.135)\end{array}$ \\
\hline Roof Type $3 \times$ Lottery & & $\begin{array}{l}-0.307 \\
(0.187)\end{array}$ & & $\begin{array}{c}-0.293^{*} \\
(0.165)\end{array}$ \\
\hline Roof Type $4 \times$ Lottery & & $\begin{array}{c}-0.378 * * * \\
(0.130)\end{array}$ & & $\begin{array}{c}-0.372 * * * \\
(0.133)\end{array}$ \\
\hline Roof Type $5 \times$ Lottery & & $\begin{array}{c}-0.301 * * \\
(0.145)\end{array}$ & & $\begin{array}{c}-0.298 * * \\
(0.148)\end{array}$ \\
\hline Roof Type $6 \times$ Lottery & & $\begin{array}{c}-0.278 * * \\
(0.131)\end{array}$ & & $\begin{array}{c}-0.293 * * \\
(0.136)\end{array}$ \\
\hline Wall Type $1 \times$ Lottery & & $\begin{array}{c}-0.494 * * * \\
(0.056)\end{array}$ & & $\begin{array}{c}-0.538 * * * \\
(0.056)\end{array}$ \\
\hline Wall Type $2 \times$ Lottery & & $\begin{array}{c}-0.464 * * * \\
(0.054)\end{array}$ & & $\begin{array}{c}-0.475 * * * \\
(0.055)\end{array}$ \\
\hline Wall Type $3 \times$ Lottery & & $\begin{array}{c}-0.470 * * * \\
(0.072)\end{array}$ & & $\begin{array}{c}-0.481 * * * \\
(0.076)\end{array}$ \\
\hline Wall Type $4 \times$ Lottery & & $\begin{array}{c}-0.367 * * * \\
(0.055)\end{array}$ & & $\begin{array}{c}-0.398 * * * \\
(0.055)\end{array}$ \\
\hline Wall Type $5 \times$ Lottery & & $\begin{array}{c}-0.312 * * * \\
(0.051)\end{array}$ & & $\begin{array}{c}-0.337 * * * \\
(0.049)\end{array}$ \\
\hline Wall Type $6 \times$ Lottery & & $\begin{array}{l}-0.391 \\
(0.305)\end{array}$ & & $\begin{array}{c}-0.412 * \\
(0.246)\end{array}$ \\
\hline Floor Type $1 \times$ Lottery & & $\begin{array}{l}1.208 * * * \\
(0.248)\end{array}$ & & $\begin{array}{l}-0.177 * \\
(0.101)\end{array}$ \\
\hline Floor Type $2 \times$ Lottery & & $\begin{array}{c}1.327 * * * \\
(0.241)\end{array}$ & & $\begin{array}{l}-0.031 \\
(0.099)\end{array}$ \\
\hline Floor Type $3 \times$ Lottery & & $\begin{array}{c}1.310^{* * *} \\
(0.242)\end{array}$ & & $\begin{array}{l}-0.045 \\
(0.096)\end{array}$ \\
\hline Floor Type $4 \times$ Lottery & & $\begin{array}{c}1.400 * * * \\
(0.257)\end{array}$ & & \\
\hline Floor Type $5 \times$ Lottery & & $\begin{array}{c}1.261 * * * \\
(0.246)\end{array}$ & & $\begin{array}{l}-0.114 \\
(0.093)\end{array}$ \\
\hline
\end{tabular}




\begin{tabular}{|c|c|c|c|c|}
\hline Floor Type $6 \times$ Lottery & & $\begin{array}{c}1.476 * * * \\
(0.242)\end{array}$ & & $\begin{array}{c}0.025 \\
(0.101)\end{array}$ \\
\hline Floor Type $7 \times$ Lottery & & $\begin{array}{c}1.393 * * * \\
(0.241)\end{array}$ & & $\begin{array}{c}0.020 \\
(0.096)\end{array}$ \\
\hline HH Has Clean Water $\times$ Lottery & & $\begin{array}{c}-0.014 \\
(0.025)\end{array}$ & & $\begin{array}{c}0.027 \\
(0.028)\end{array}$ \\
\hline HH Has Own Latrine $\times$ Lottery & & $\begin{array}{c}0.020 \\
(0.023)\end{array}$ & & $\begin{array}{c}0.026 \\
(0.025)\end{array}$ \\
\hline HH Has Square Latrine $\times$ Lottery & & $\begin{array}{c}-0.082 * * * \\
(0.029)\end{array}$ & & $\begin{array}{c}-0.097 * * * \\
(0.031)\end{array}$ \\
\hline HH Has Septic Tank $\times$ Lottery & & $\begin{array}{c}0.006 \\
(0.029)\end{array}$ & & $\begin{array}{c}0.005 \\
(0.032)\end{array}$ \\
\hline HH Has PLN Electricity $\times$ Lottery & & $\begin{array}{c}-0.137 * * * \\
(0.035)\end{array}$ & & $\begin{array}{c}-0.121^{* * *} \\
(0.037)\end{array}$ \\
\hline Log Per-Capita HH Expenditure $\times$ Lottery & & $\begin{array}{c}-0.073 * * * \\
(0.017)\end{array}$ & & $\begin{array}{c}-0.070 * * * \\
(0.019)\end{array}$ \\
\hline Log HH Size $\times$ Lottery & & $\begin{array}{c}0.003 \\
(0.026)\end{array}$ & & $\begin{array}{l}-0.030 \\
(0.029)\end{array}$ \\
\hline Observations & 14757 & 14757 & 15667 & 15667 \\
\hline$R^{2}$ & 0.258 & 0.291 & 0.242 & 0.270 \\
\hline Control Mean & 0.091 & 0.091 & 0.131 & 0.131 \\
\hline F-statistic & 507.797 & 59.741 & 456.783 & 56.969 \\
\hline
\end{tabular}

Note: This table replicates Table 1, but includes coefficients for interactions of baseline controls with the treatment assignment lottery variable (Columns 2 and 4). We omit coefficients for interactions that were dropped from both regressions due to collinearity. Standard errors, clustered by sub-district, are shown in parentheses.

$* p<0.1 * * p<0.05 * * * p<0.01$. 
Appendix Table 8: IV Effect of PKH on Health-Seeking Behaviors (Currently Receiving PKH)

\begin{tabular}{|c|c|c|c|c|}
\hline \multirow[b]{2}{*}{ Outcome: } & \multicolumn{2}{|c|}{ 2-Year } & \multicolumn{2}{|c|}{ 6-Year } \\
\hline & $\begin{array}{c}\text { (1) } \\
\text { Lottery Only }\end{array}$ & $\begin{array}{c}\text { (2) } \\
\text { Lottery + Assets }\end{array}$ & $\begin{array}{c}\text { (3) } \\
\text { Lottery Only }\end{array}$ & $\begin{array}{c}\text { (4) } \\
\text { Lottery + Assets }\end{array}$ \\
\hline \multicolumn{5}{|l|}{ Panel A: Maternal Health-Seeking Behaviors } \\
\hline \multirow[t]{4}{*}{ Number of pre-natal visits } & $1.107 * *$ & $1.000 * *$ & 0.979 & 0.693 \\
\hline & $(0.512)$ & $(0.424)$ & $(0.822)$ & $(0.620)$ \\
\hline & 2,771 & 2,771 & 2,855 & 2,855 \\
\hline & 6.585 & 6.585 & 7.286 & 7.286 \\
\hline \multirow[t]{4}{*}{ Good assisted delivery } & $0.115^{* *}$ & $0.130 * *$ & $0.284 * * *$ & $0.177 * *$ \\
\hline & $(0.056)$ & $(0.051)$ & $(0.073)$ & $(0.069)$ \\
\hline & 2,100 & 2,100 & 2,154 & 2,154 \\
\hline & 0.640 & 0.640 & 0.770 & 0.770 \\
\hline \multirow[t]{4}{*}{ Delivery at health facility } & $0.112^{*}$ & 0.086 & $0.209 * *$ & $0.130^{*}$ \\
\hline & $(0.062)$ & $(0.052)$ & $(0.081)$ & $(0.075)$ \\
\hline & 2,100 & 2,100 & 2,154 & 2,154 \\
\hline & 0.457 & 0.457 & 0.725 & 0.725 \\
\hline \multirow[t]{4}{*}{ Number of post-natal visits } & $1.024 * *$ & $1.199 * * *$ & 0.314 & 0.116 \\
\hline & $(0.400)$ & $(0.343)$ & $(0.511)$ & $(0.360)$ \\
\hline & 2,100 & 2,100 & 2,154 & 2,154 \\
\hline & 1.391 & 1.391 & 1.970 & 1.970 \\
\hline \multirow[t]{4}{*}{$90+$ iron pills during pregnancy } & 0.025 & 0.009 & -0.044 & -0.026 \\
\hline & $(0.049)$ & $(0.042)$ & $(0.056)$ & $(0.048)$ \\
\hline & 2,202 & 2,202 & 2,265 & 2,265 \\
\hline & 0.179 & 0.179 & 0.131 & 0.131 \\
\hline \multicolumn{5}{|l|}{ Panel B: Child Immunizations and Health Visits } \\
\hline \multirow[t]{4}{*}{ All immunizations complete for age } & 0.033 & 0.025 & 0.089 & $0.119 * *$ \\
\hline & $(0.044)$ & $(0.040)$ & $(0.055)$ & $(0.049)$ \\
\hline & 7,769 & 7,769 & 9,989 & 9,989 \\
\hline & 0.425 & 0.425 & 0.529 & 0.529 \\
\hline \multirow[t]{4}{*}{$\%$ of immunizations received for age } & 0.038 & 0.039 & $0.055^{*}$ & $0.061 * *$ \\
\hline & $(0.029)$ & $(0.028)$ & $(0.033)$ & $(0.031)$ \\
\hline & 7,769 & 7,769 & 9,989 & 9,989 \\
\hline & 0.754 & 0.754 & 0.786 & 0.786 \\
\hline \multirow[t]{4}{*}{ Times received Vitamin A (6 months - 2 years) } & -0.022 & -0.170 & -0.111 & 0.094 \\
\hline & $(0.208)$ & $(0.243)$ & $(0.238)$ & $(0.179)$ \\
\hline & 1,428 & 1,428 & 1,498 & 1,498 \\
\hline & 1.639 & 1.639 & 1.817 & 1.817 \\
\hline \multirow[t]{4}{*}{ Times weighed in last 3 months ( $0-60$ months) } & $0.919 * * *$ & $0.871 * * *$ & 0.307 & 0.305 \\
\hline & $(0.130)$ & $(0.115)$ & $(0.236)$ & $(0.212)$ \\
\hline & 7,934 & 7,934 & 4,373 & 4,373 \\
\hline & 1.790 & 1.790 & 1.954 & 1.954 \\
\hline
\end{tabular}

Note: This table replicates Table 2, but redefines our PKH receipt indicator as those households currently receiving PKH, rather than those that have ever received PKH. Standard errors, clustered by sub-district, are shown in parentheses.

$* p<0.1 * * p<0.05 * * * p<0.01$. 


\begin{tabular}{|c|c|c|c|c|}
\hline \multirow[b]{2}{*}{ Outcome: } & \multicolumn{2}{|c|}{ 2-Year } & \multicolumn{2}{|c|}{ 6-Year } \\
\hline & $\begin{array}{c}\text { (1) } \\
\text { Lottery Only }\end{array}$ & $\begin{array}{c}\text { (2) } \\
\text { Lottery + Assets }\end{array}$ & $\begin{array}{c}\text { (3) } \\
\text { Lottery Only }\end{array}$ & $\begin{array}{c}\text { (4) } \\
\text { Lottery + Assets }\end{array}$ \\
\hline \multirow[t]{4}{*}{ Stunted } & -0.028 & -0.024 & $-0.109 * *$ & $-0.129 * * *$ \\
\hline & $(0.035)$ & $(0.031)$ & $(0.048)$ & $(0.044)$ \\
\hline & 7,707 & 7,707 & 5,211 & 5,211 \\
\hline & 0.513 & 0.513 & 0.390 & 0.390 \\
\hline \multirow[t]{4}{*}{ Severely stunted } & -0.023 & -0.014 & $-0.123 * * *$ & $-0.133 * * *$ \\
\hline & $(0.034)$ & $(0.031)$ & $(0.036)$ & $(0.036)$ \\
\hline & 7,707 & 7,707 & 5,211 & 5,211 \\
\hline & 0.306 & 0.306 & 0.180 & 0.180 \\
\hline \multirow[t]{4}{*}{ Malnourished } & -0.008 & -0.024 & -0.011 & $-0.066^{*}$ \\
\hline & $(0.028)$ & $(0.027)$ & $(0.040)$ & $(0.039)$ \\
\hline & 7,860 & 7,860 & 5,231 & 5,231 \\
\hline & 0.332 & 0.332 & 0.274 & 0.274 \\
\hline \multirow[t]{4}{*}{ Severely malnourished } & 0.004 & -0.010 & -0.004 & -0.028 \\
\hline & $(0.018)$ & $(0.018)$ & $(0.025)$ & $(0.029)$ \\
\hline & 7,860 & 7,860 & 5,231 & 5,231 \\
\hline & 0.097 & 0.097 & 0.068 & 0.068 \\
\hline \multicolumn{5}{|l|}{ Panel B: Acute Child Morbidity } \\
\hline \multirow[t]{4}{*}{ Diarrhea last month } & 0.041 & $0.052 * *$ & -0.016 & -0.001 \\
\hline & $(0.029)$ & $(0.026)$ & $(0.044)$ & $(0.038)$ \\
\hline & 7,931 & 7,931 & 4,369 & 4,369 \\
\hline & 0.199 & 0.199 & 0.221 & 0.221 \\
\hline \multirow[t]{4}{*}{ Fever or cough last month } & 0.050 & 0.048 & 0.014 & 0.001 \\
\hline & $(0.039)$ & $(0.036)$ & $(0.058)$ & $(0.049)$ \\
\hline & 7,933 & 7,933 & 4,376 & 4,376 \\
\hline & 0.545 & 0.545 & 0.535 & 0.535 \\
\hline \multicolumn{5}{|l|}{ Panel C: Maternal Knowledge Outcomes } \\
\hline \multirow[t]{4}{*}{ Knows birth weight } & $0.105 * *$ & $0.148 * * *$ & $0.187 * * *$ & $0.146^{* *}$ \\
\hline & $(0.049)$ & $(0.048)$ & $(0.064)$ & $(0.064)$ \\
\hline & 2,064 & 2,064 & 2,129 & 2,129 \\
\hline & 0.742 & 0.742 & 0.838 & 0.838 \\
\hline \multirow[t]{4}{*}{ Mother's composite knowledge \% (of 5) } & 0.014 & 0.015 & 0.022 & $0.030^{* *}$ \\
\hline & $(0.013)$ & $(0.013)$ & $(0.016)$ & $(0.015)$ \\
\hline & 15,047 & 15,047 & 16,734 & 16,734 \\
\hline & 0.545 & 0.545 & 0.572 & 0.572 \\
\hline
\end{tabular}

Note: This table replicates Table 3, but redefines our PKH receipt indicator as those households currently receiving PKH, rather than those that have ever received PKH. Standard errors, clustered by sub-district, are shown in parentheses.

$* p<0.1 * * p<0.05 * * * p<0.01$. 


\begin{tabular}{|c|c|c|}
\hline Outcome: & $\frac{\text { 2-Year }}{(1)}$ Lottery Only & $\begin{array}{c}\text { 6-Year } \\
\text { (2) } \\
\text { Lottery Only }\end{array}$ \\
\hline $\begin{array}{l}\text { Panel A: Maternal Health-Seeking Behaviors } \\
\text { Number of pre-natal visits }\end{array}$ & $\begin{array}{c}1.021 * * \\
(0.519) \\
2,771 \\
6.585\end{array}$ & $\begin{array}{c}0.715 \\
(0.660) \\
2,855 \\
7.286\end{array}$ \\
\hline Good assisted delivery & $\begin{array}{c}0.124 * * \\
(0.059) \\
2,100 \\
0.640\end{array}$ & $\begin{array}{c}0.224 * * * \\
(0.064) \\
2,154 \\
0.770\end{array}$ \\
\hline Delivery at health facility & $\begin{array}{c}0.127 * \\
(0.069) \\
2,100 \\
0.457\end{array}$ & $\begin{array}{c}0.161 * * \\
(0.070) \\
2,154 \\
0.725\end{array}$ \\
\hline Number of post-natal visits & $\begin{array}{c}1.020 * * \\
(0.414) \\
2,100 \\
1.391\end{array}$ & $\begin{array}{c}0.334 \\
(0.461) \\
2,154 \\
1.970\end{array}$ \\
\hline $90+$ iron pills during pregnancy & $\begin{array}{c}0.008 \\
(0.049) \\
2,202 \\
0.179\end{array}$ & $\begin{array}{c}-0.038 \\
(0.048) \\
2,265 \\
0.131\end{array}$ \\
\hline $\begin{array}{l}\text { Panel B: Child Immunizations and Health Visits } \\
\text { All immunizations complete for age }\end{array}$ & $\begin{array}{c}0.027 \\
(0.049) \\
7,769 \\
0.425\end{array}$ & $\begin{array}{c}0.079 \\
(0.051) \\
9,989 \\
0.529\end{array}$ \\
\hline$\%$ of immunizations received for age & $\begin{array}{c}0.031 \\
(0.031) \\
7,769 \\
0.754\end{array}$ & $\begin{array}{c}0.047 \\
(0.030) \\
9,989 \\
0.786\end{array}$ \\
\hline Times received Vitamin A (6 months - 2 years) & $\begin{array}{c}0.042 \\
(0.209) \\
1,428 \\
1.639\end{array}$ & $\begin{array}{c}-0.197 \\
(0.234) \\
1,498 \\
1.817\end{array}$ \\
\hline Times weighed in last 3 months ( $0-5$ years $)$ & $\begin{array}{c}0.876 * * * \\
(0.135) \\
7,934 \\
1.790\end{array}$ & $\begin{array}{c}0.279 \\
(0.201) \\
4,373 \\
1.954\end{array}$ \\
\hline
\end{tabular}

Note: This table replicates Columns 1 and 3 of Table 2, but does not include any baseline or age-bin controls. Since the instruments used in Columns 2 and 4 of Table 2 involve baseline assets and household characteristics, we do not replicate them here. Standard errors, clustered by sub-district, are shown in parentheses.

$* p<0.1 * * p<0.05 * * * p<0.01$. 
Appendix Table 11: IV Effect of PKH on Child Nutrition and Health Outcomes, 0-60 Months (No Controls)

\begin{tabular}{|c|c|c|}
\hline \multirow[b]{3}{*}{ Outcome: } & 2-Year & 6-Year \\
\hline & (1) & (2) \\
\hline & Lottery Only & Lottery Only \\
\hline \multirow[t]{4}{*}{ Stunted } & -0.019 & $-0.096 * *$ \\
\hline & $(0.036)$ & $(0.043)$ \\
\hline & 7,707 & 5,211 \\
\hline & 0.513 & 0.390 \\
\hline \multirow[t]{4}{*}{ Severely stunted } & -0.015 & $-0.104 * * *$ \\
\hline & $(0.036)$ & $(0.031)$ \\
\hline & 7,707 & 5,211 \\
\hline & 0.306 & 0.180 \\
\hline \multirow[t]{4}{*}{ Malnourished } & -0.007 & -0.017 \\
\hline & $(0.034)$ & $(0.039)$ \\
\hline & 7,860 & 5,231 \\
\hline & 0.332 & 0.274 \\
\hline \multirow[t]{4}{*}{ Severely malnourished } & 0.006 & -0.007 \\
\hline & $(0.021)$ & $(0.022)$ \\
\hline & 7,860 & 5,231 \\
\hline & 0.097 & 0.068 \\
\hline \multicolumn{3}{|l|}{ Panel B: Acute Child Morbidity } \\
\hline \multirow[t]{4}{*}{ Diarrhea last month } & 0.047 & -0.010 \\
\hline & $(0.031)$ & $(0.038)$ \\
\hline & 7,931 & 4,369 \\
\hline & 0.199 & 0.221 \\
\hline \multirow[t]{4}{*}{ Fever or cough last month } & 0.045 & 0.015 \\
\hline & $(0.044)$ & $(0.051)$ \\
\hline & 7,933 & 4,376 \\
\hline & 0.545 & 0.535 \\
\hline \multicolumn{3}{|l|}{ Panel C: Maternal Knowledge Outcomes } \\
\hline \multirow[t]{4}{*}{ Knows birth weight } & $0.118 * *$ & $0.146 * *$ \\
\hline & $(0.060)$ & $(0.057)$ \\
\hline & 2,064 & 2,129 \\
\hline & 0.742 & 0.838 \\
\hline \multirow[t]{4}{*}{ Mother's composite knowledge \% (of 5) } & 0.011 & 0.015 \\
\hline & $(0.014)$ & $(0.013)$ \\
\hline & 15,047 & 16,734 \\
\hline & 0.545 & 0.572 \\
\hline
\end{tabular}

Note: This table replicates Columns 1 and 3 of Table 3, but does not include any baseline or age-bin controls. Since the instruments used in Columns 2 and 4 of Table 3 involve baseline assets and household characteristics, we do not replicate them here. Standard errors, clustered by sub-district, are shown in parentheses.

$* p<0.1 * * p<0.05 * * * p<0.01$. 
Appendix Table 12: IV Effect of PKH on Incentivized Education Indicators (No Controls)

\begin{tabular}{|c|c|c|}
\hline Outcome: & $\begin{array}{c}\text { 2-Year } \\
\text { Lottery Only }\end{array}$ & $\begin{array}{c}\text { 6-Year } \\
\text { (2) } \\
\text { Lottery Only }\end{array}$ \\
\hline \multicolumn{3}{|l|}{ Panel A: Enrollment for Ages 7-15 } \\
\hline Enrolled in school (any level) & $\begin{array}{c}0.056^{* * *} \\
(0.014) \\
17,525 \\
0.903\end{array}$ & $\begin{array}{c}0.035 * * * \\
(0.013) \\
17,720 \\
0.924\end{array}$ \\
\hline$>85 \%$ attendance last two weeks & $\begin{array}{c}0.061 * * * \\
(0.017) \\
17,437 \\
0.830\end{array}$ & $\begin{array}{c}0.051 * * * \\
(0.018) \\
17,710 \\
0.856\end{array}$ \\
\hline $\begin{array}{l}\text { Panel B: Outcomes for Ages 7-12 } \\
\text { Enrolled in school (any level) }\end{array}$ & $\begin{array}{c}0.035 * * * \\
(0.009) \\
11,957 \\
0.960\end{array}$ & $\begin{array}{c}0.010 \\
(0.008) \\
11,963 \\
0.972\end{array}$ \\
\hline Enrolled in primary school & $\begin{array}{c}0.011 \\
(0.014) \\
11,957 \\
0.887\end{array}$ & $\begin{array}{c}0.010 \\
(0.016) \\
11,963 \\
0.879\end{array}$ \\
\hline$>85 \%$ attendance last two weeks & $\begin{array}{c}0.037 * * \\
(0.016) \\
11,893 \\
0.881\end{array}$ & $\begin{array}{c}0.030^{*} \\
(0.017) \\
11,957 \\
0.895\end{array}$ \\
\hline \multicolumn{3}{|c|}{ Panel C: Primary-Secondary Transition, Ages 7-15 } \\
\hline Transitioned from primary to secondary & $\begin{array}{c}0.077 * * * \\
(0.026) \\
5,538 \\
0.891\end{array}$ & $\begin{array}{c}0.025 \\
(0.019) \\
6,049 \\
0.941\end{array}$ \\
\hline \multicolumn{3}{|l|}{ Panel D: Outcomes for Ages 13-15 } \\
\hline Enrolled in school (any level) & $\begin{array}{c}0.096 * * * \\
(0.034) \\
5,568 \\
0.783\end{array}$ & $\begin{array}{c}0.079 * * * \\
(0.030) \\
5,757 \\
0.826\end{array}$ \\
\hline Enrolled in secondary school & $\begin{array}{c}0.066^{*} \\
(0.039) \\
5,568 \\
0.585\end{array}$ & $\begin{array}{c}0.051 \\
(0.034) \\
5,757 \\
0.609\end{array}$ \\
\hline$>85 \%$ attendance last two weeks & $\begin{array}{c}0.107 * * * \\
(0.036) \\
5,544 \\
0.723\end{array}$ & $\begin{array}{c}0.089 * * * \\
(0.032) \\
5,753 \\
0.777\end{array}$ \\
\hline
\end{tabular}

Note: This table replicates Columns 1 and 3 of Table 4, but does not include any baseline controls. Since the instruments used in Columns 2 and 4 of Table 4 involve baseline assets and household characteristics, we do not replicate them here. Standard errors, clustered by sub-district, are shown in parentheses.

$* p<0.1 * * p<0.05 * * * p<0.01$. 
Appendix Table 13: IV Effect of PKH on Anthropometric Outcomes, by Gender

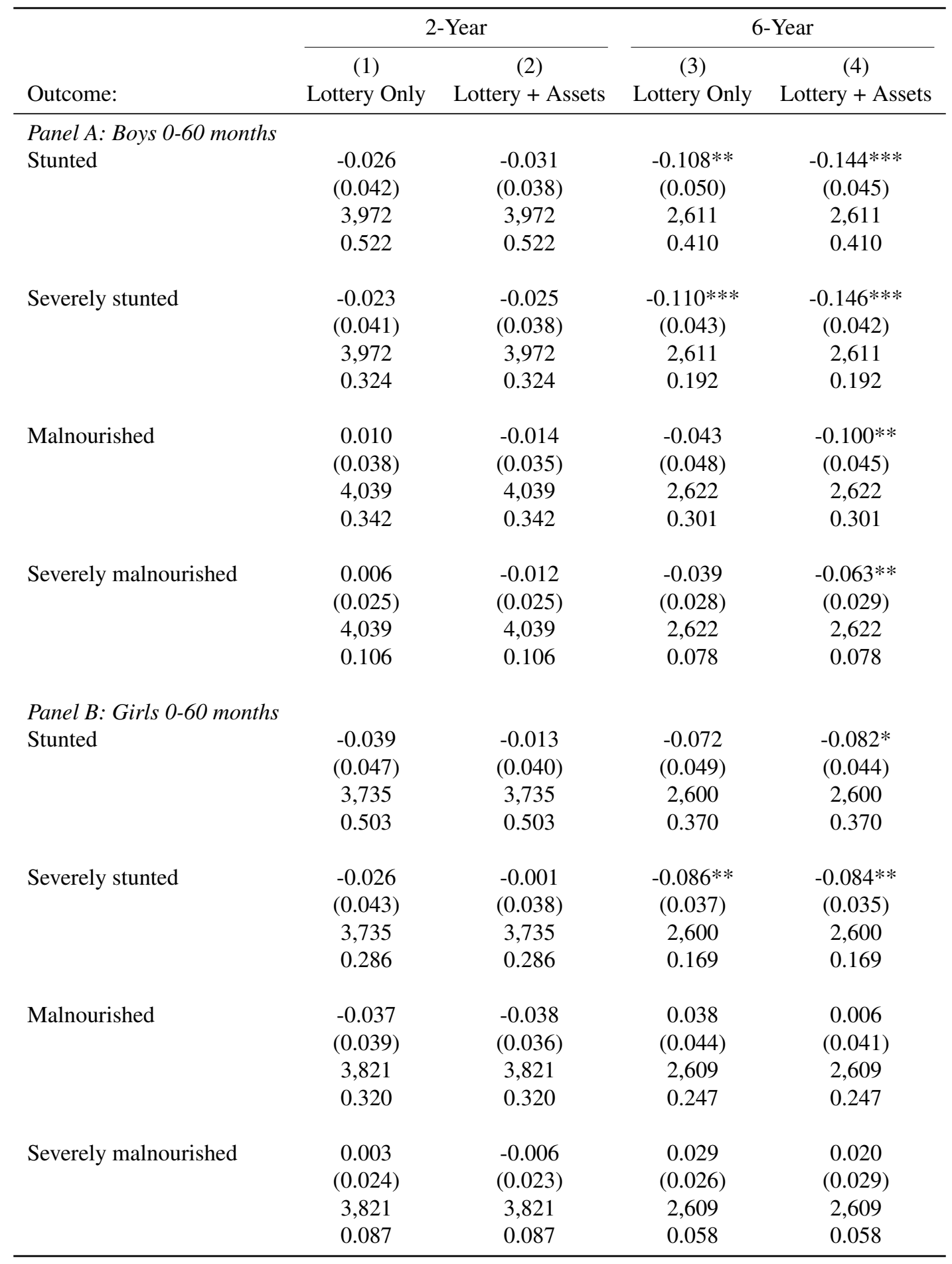

Note: This table disaggregates the anthropometric outcomes shown in Table 3 by child's gender. Standard errors, clustered by sub-district, are shown in parentheses.

$* p<0.1 * * p<0.05 * * * p<0.01$. 
Appendix Table 14: IV Effect of PKH on Breastfeeding and Household Sanitation Outcomes

\begin{tabular}{|c|c|c|c|c|}
\hline \multirow[b]{3}{*}{ Outcome: } & \multicolumn{2}{|c|}{ 2-Year } & \multicolumn{2}{|c|}{ 6-Year } \\
\hline & (1) & $(2)$ & (3) & (4) \\
\hline & Lottery Only & Lottery + Assets & Lottery Only & Lottery + Assets \\
\hline \multicolumn{5}{|c|}{ Panel A: Maternal Knowledge of Proper Health Practices (Ages <35) } \\
\hline \multirow[t]{4}{*}{ Mother's composite knowledge \% (of 5) } & 0.018 & 0.016 & 0.020 & 0.018 \\
\hline & $(0.017)$ & $(0.015)$ & $(0.018)$ & $(0.015)$ \\
\hline & 6,803 & 6,803 & 6,093 & 6,093 \\
\hline & 0.547 & 0.547 & 0.580 & 0.580 \\
\hline \multirow[t]{4}{*}{$\%$ of breastfeeding questions correct (of 2 ) } & 0.033 & 0.030 & -0.007 & 0.011 \\
\hline & $(0.024)$ & $(0.022)$ & $(0.030)$ & $(0.026)$ \\
\hline & 6,803 & 6,803 & 6,093 & 6,093 \\
\hline & 0.425 & 0.425 & 0.524 & 0.524 \\
\hline \multirow[t]{4}{*}{$\%$ of diarrhea questions correct (of 2) } & -0.011 & -0.012 & 0.006 & -0.011 \\
\hline & $(0.025)$ & $(0.022)$ & $(0.027)$ & $(0.024)$ \\
\hline & 6,803 & 6,803 & 6,093 & 6,093 \\
\hline & 0.521 & 0.521 & 0.502 & 0.502 \\
\hline \multirow[t]{4}{*}{ Pre-natal visits question correct } & 0.045 & 0.046 & $0.102 * * *$ & $0.088 * * *$ \\
\hline & $(0.029)$ & $(0.029)$ & $(0.031)$ & $(0.029)$ \\
\hline & 6,803 & 6,803 & 6,092 & 6,092 \\
\hline & 0.846 & 0.846 & 0.849 & 0.849 \\
\hline \multicolumn{5}{|c|}{ Panel B: Children's Breastfeeding Outcomes (0-60 Months) } \\
\hline \multirow[t]{4}{*}{ Child ever been breastfed } & 0.007 & 0.009 & 0.005 & 0.003 \\
\hline & $(0.009)$ & $(0.008)$ & $(0.018)$ & $(0.015)$ \\
\hline & 7,934 & 7,934 & 4,376 & 4,376 \\
\hline & 0.973 & 0.973 & 0.958 & 0.958 \\
\hline \multirow[t]{4}{*}{ Breastfed within 1 hour of birth } & -0.005 & 0.001 & -0.036 & -0.002 \\
\hline & $(0.041)$ & $(0.039)$ & $(0.045)$ & $(0.041)$ \\
\hline & 7,861 & 7,861 & 4,336 & 4,336 \\
\hline & 0.652 & 0.652 & 0.705 & 0.705 \\
\hline \multirow[t]{4}{*}{ Exclusively breastfed for 3 months after birth } & 0.023 & 0.039 & 0.059 & 0.069 \\
\hline & $(0.034)$ & $(0.033)$ & $(0.057)$ & $(0.050)$ \\
\hline & 7,912 & 7,912 & 4,368 & 4,368 \\
\hline & 0.366 & 0.366 & 0.468 & 0.468 \\
\hline \multicolumn{5}{|l|}{ Panel C: Household Investment in Sanitation } \\
\hline \multirow[t]{4}{*}{ Household has piped water } & -0.021 & -0.021 & 0.002 & 0.006 \\
\hline & $(0.026)$ & $(0.021)$ & $(0.026)$ & $(0.024)$ \\
\hline & 14,600 & 14,600 & 15,499 & 15,499 \\
\hline & 0.126 & 0.126 & 0.125 & 0.125 \\
\hline \multirow[t]{4}{*}{ Household has own latrine } & 0.039 & 0.034 & -0.016 & -0.012 \\
\hline & $(0.030)$ & $(0.028)$ & $(0.035)$ & $(0.034)$ \\
\hline & 14,600 & 14,600 & 15,499 & 15,499 \\
\hline & 0.466 & 0.466 & 0.560 & 0.560 \\
\hline \multirow[t]{4}{*}{ Household has square latrine } & 0.037 & 0.040 & -0.037 & -0.021 \\
\hline & $(0.030)$ & $(0.027)$ & $(0.036)$ & $(0.034)$ \\
\hline & 14,600 & 14,600 & 15,499 & 15,499 \\
\hline & 0.364 & 0.364 & 0.498 & 0.498 \\
\hline \multirow[t]{4}{*}{ Household has own septic tank } & 0.038 & 0.042 & 0.023 & 0.032 \\
\hline & $(0.029)$ & $(0.027)$ & $(0.038)$ & $(0.035)$ \\
\hline & 14,600 & 14,600 & 15,499 & 15,499 \\
\hline & 0.336 & 0.336 & 0.455 & 0.455 \\
\hline \multirow[t]{4}{*}{ Household has PLN electricity } & 0.014 & 0.012 & -0.006 & -0.007 \\
\hline & $(0.021)$ & $(0.023)$ & $(0.025)$ & $(0.028)$ \\
\hline & 14,600 & 14,600 & 15,499 & 15,499 \\
\hline & 0.860 & 0.860 & 0.917 & 0.917 \\
\hline
\end{tabular}

Note: This table explores the effect of PKH receipt on several different health and sanitation indicators. For the outcomes in Panel A, surveyed women aged 16-49 were asked a set of questions pertaining to proper feeding and childrearing practices. "Mother's composite knowledge \%" refers to the number of correct answers (out of five) converted to a percent score. The following three outcomes pertain to the disaggregated questions. Panel B regressions include age-bin controls for each month of age up to 1 year, and for each quarter-year of age between 1 and 5 years. Baseline controls and fixed effects are as listed in Table 1. Standard errors, clustered by sub-district, are shown in parentheses. $* p<0.1, * * p<0.05, * * * p<0.01$. 
Appendix Table 15: IV Effect of PKH on Household Empowerment for Young Mothers (Age <35)

\begin{tabular}{|c|c|c|c|c|}
\hline \multirow[b]{3}{*}{ Outcome: } & \multicolumn{2}{|c|}{ 2-Year } & \multicolumn{2}{|c|}{ 6-Year } \\
\hline & (1) & $(2)$ & (3) & (4) \\
\hline & Lottery Only & Lottery + Assets & Lottery Only & Lottery + Assets \\
\hline \multirow[t]{4}{*}{ Mother involved: education } & -0.004 & 0.015 & $0.072 *$ & $0.075 * *$ \\
\hline & $(0.041)$ & $(0.039)$ & $(0.039)$ & $(0.034)$ \\
\hline & 6,206 & 6,206 & 5,604 & 5,604 \\
\hline & 0.804 & 0.804 & 0.776 & 0.776 \\
\hline \multirow[t]{4}{*}{ Mother alone: education } & 0.014 & 0.016 & 0.032 & 0.039 \\
\hline & $(0.025)$ & $(0.021)$ & $(0.031)$ & $(0.026)$ \\
\hline & 6,206 & 6,206 & 5,604 & 5,604 \\
\hline & 0.122 & 0.122 & 0.127 & 0.127 \\
\hline \multirow[t]{4}{*}{ Mother involved: health } & 0.029 & 0.042 & $0.075 * *$ & $0.077 * *$ \\
\hline & $(0.036)$ & $(0.033)$ & $(0.036)$ & $(0.032)$ \\
\hline & 6,442 & 6,442 & 5,730 & 5,730 \\
\hline & 0.838 & 0.838 & 0.800 & 0.800 \\
\hline \multirow[t]{4}{*}{ Mother alone: health } & $0.055^{*}$ & $0.048^{*}$ & 0.054 & $0.055^{* *}$ \\
\hline & $(0.032)$ & $(0.029)$ & $(0.033)$ & $(0.028)$ \\
\hline & 6,442 & 6,442 & 5,730 & 5,730 \\
\hline & 0.177 & 0.177 & 0.160 & 0.160 \\
\hline \multirow[t]{4}{*}{ Mother involved: discipline } & 0.036 & $0.055^{*}$ & $0.077 * *$ & $0.062 *$ \\
\hline & $(0.034)$ & $(0.032)$ & $(0.037)$ & $(0.033)$ \\
\hline & 6,405 & 6,405 & 5,662 & 5,662 \\
\hline & 0.823 & 0.823 & 0.789 & 0.789 \\
\hline \multirow[t]{4}{*}{ Mother alone: discipline } & 0.015 & 0.001 & 0.028 & 0.022 \\
\hline & $(0.031)$ & $(0.028)$ & $(0.032)$ & $(0.027)$ \\
\hline & 6,405 & 6,405 & 5,662 & 5,662 \\
\hline & 0.201 & 0.201 & 0.162 & 0.162 \\
\hline \multirow[t]{4}{*}{ Mother involved: have another baby } & 0.014 & 0.012 & 0.059 & $0.064^{*}$ \\
\hline & $(0.036)$ & $(0.033)$ & $(0.040)$ & $(0.035)$ \\
\hline & 6,283 & 6,283 & 5,575 & 5,575 \\
\hline & 0.845 & 0.845 & 0.787 & 0.787 \\
\hline \multirow[t]{4}{*}{ Mother alone: have another baby } & 0.008 & 0.003 & 0.018 & 0.017 \\
\hline & $(0.021)$ & $(0.019)$ & $(0.028)$ & $(0.024)$ \\
\hline & 6,283 & 6,283 & 5,575 & 5,575 \\
\hline & 0.085 & 0.085 & 0.118 & 0.118 \\
\hline
\end{tabular}

Note: This table explores various outcomes pertaining to women's empowerment and status within the household, focusing on mothers younger than 35 years of age. Each pair of outcomes corresponds to a survey question in which the respondent was asked who in the household is involved in making various decisions pertaining to children. "Mother involved" outcomes indicate that a mother included herself on the list of household members who were involved in making decisions, which may or may not include other household members. "Mother alone" outcomes indicate that a mother listed only herself as involved in making such decisions. Baseline controls and fixed effects are as listed in Table 1. Standard errors, clustered by sub-district, are shown in parentheses.

$* p<0.1 * * p<0.05 * * * p<0.01$. 
Appendix Table 16: IV Effect of PKH on Child Food Consumption in Last Week (Ages 18-60 Months)

\begin{tabular}{|c|c|c|c|c|}
\hline \multirow[b]{2}{*}{ Outcome: } & \multicolumn{2}{|c|}{ 2-Year } & \multicolumn{2}{|c|}{ 6-Year } \\
\hline & $\begin{array}{c}\text { (1) } \\
\text { Lottery Only }\end{array}$ & $\begin{array}{c}(2) \\
\text { Lottery }+ \text { Assets }\end{array}$ & $\begin{array}{c}\text { (3) } \\
\text { Lottery Only }\end{array}$ & $\begin{array}{c}\text { (4) } \\
\text { Lottery + Assets }\end{array}$ \\
\hline Drank milk last week & $\begin{array}{c}0.097 * * \\
(0.038) \\
6,392 \\
0.417\end{array}$ & $\begin{array}{c}0.106 * * * \\
(0.033) \\
6,392 \\
0.417\end{array}$ & $\begin{array}{c}-0.028 \\
(0.056) \\
2,669 \\
0.523\end{array}$ & $\begin{array}{c}0.015 \\
(0.051) \\
2,669 \\
0.523\end{array}$ \\
\hline Ate egg last week & $\begin{array}{c}0.101 * * * \\
(0.033) \\
6,392 \\
0.674\end{array}$ & $\begin{array}{c}0.124 * * * \\
(0.032) \\
6,392 \\
0.674\end{array}$ & $\begin{array}{c}0.021 \\
(0.048) \\
2,669 \\
0.716\end{array}$ & $\begin{array}{c}0.053 \\
(0.045) \\
2,669 \\
0.716\end{array}$ \\
\hline Ate beef or pork last week & $\begin{array}{c}-0.046 \\
(0.039) \\
6,392 \\
0.135\end{array}$ & $\begin{array}{c}-0.023 \\
(0.032) \\
6,392 \\
0.135\end{array}$ & $\begin{array}{c}0.031 \\
(0.052) \\
2,669 \\
0.161\end{array}$ & $\begin{array}{c}0.056 \\
(0.044) \\
2,669 \\
0.161\end{array}$ \\
\hline Ate chicken, duck, or fish last week & $\begin{array}{c}0.006 \\
(0.031) \\
6,392 \\
0.843\end{array}$ & $\begin{array}{c}0.018 \\
(0.032) \\
6,392 \\
0.843\end{array}$ & $\begin{array}{c}-0.067 \\
(0.042) \\
2,669 \\
0.838\end{array}$ & $\begin{array}{c}-0.058 \\
(0.042) \\
2,669 \\
0.838\end{array}$ \\
\hline Ate rice last week & $\begin{array}{c}-0.001 \\
(0.009) \\
6,392 \\
0.981\end{array}$ & $\begin{array}{c}0.006 \\
(0.008) \\
6,392 \\
0.981\end{array}$ & $\begin{array}{c}-0.023 \\
(0.016) \\
2,669 \\
0.981\end{array}$ & $\begin{array}{c}-0.018 \\
(0.014) \\
2,669 \\
0.981\end{array}$ \\
\hline Ate other grain or noodles last week & $\begin{array}{c}0.007 \\
(0.037) \\
6,392 \\
0.722\end{array}$ & $\begin{array}{c}0.022 \\
(0.037) \\
6,392 \\
0.722\end{array}$ & $\begin{array}{c}-0.008 \\
(0.051) \\
2,669 \\
0.695\end{array}$ & $\begin{array}{c}0.020 \\
(0.045) \\
2,669 \\
0.695\end{array}$ \\
\hline Ate fruit, vegetables, or tubers last week & $\begin{array}{c}-0.011 \\
(0.009) \\
6,392 \\
0.982\end{array}$ & $\begin{array}{c}-0.005 \\
(0.008) \\
6,392 \\
0.982\end{array}$ & $\begin{array}{c}-0.016 \\
(0.024) \\
2,669 \\
0.960\end{array}$ & $\begin{array}{c}-0.030 \\
(0.023) \\
2,669 \\
0.960\end{array}$ \\
\hline Ate snacks or sweets last week & $\begin{array}{c}-0.034 \\
(0.030) \\
6,392 \\
0.863\end{array}$ & $\begin{array}{c}-0.007 \\
(0.033) \\
6,392 \\
0.863\end{array}$ & $\begin{array}{c}-0.031 \\
(0.041) \\
2,669 \\
0.836\end{array}$ & $\begin{array}{c}-0.012 \\
(0.039) \\
2,669 \\
0.836\end{array}$ \\
\hline
\end{tabular}

Note: Outcomes are dummy variables indicating whether a child had eaten the specific food category in the past week. Baseline controls and fixed effects are as listed in Table 1. Regressions also include age-bin controls as described in Table 3. Children younger than 18 months were not surveyed about food consumption. Standard errors, clustered by sub-district, are shown in parentheses.

$* p<0.1 * * p<0.05 * * * p<0.01$. 
Appendix Table 17: IV Effect of PKH on Incentivized Education Indicators, by Gender (6-Year Follow-Up)

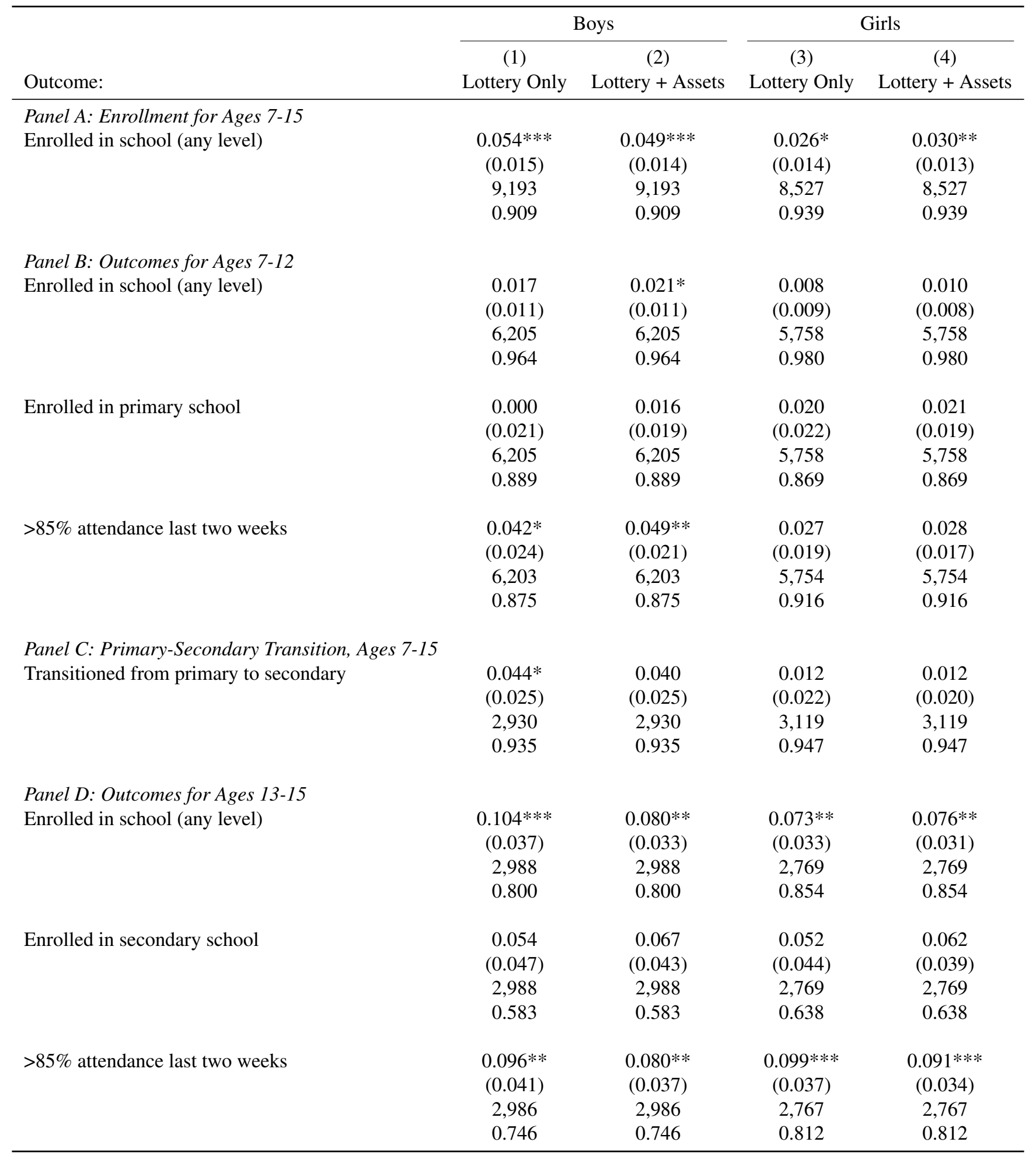

Note: This table disaggregates the 6-year education outcomes in Table 4 by child's gender. Standard errors, clustered by subdistrict, are shown in parentheses.

$* p<0.1 * * p<0.05 * * * p<0.01$. 
Appendix Table 18: IV Effect of PKH on Child Labor, by Gender (6-Year Follow-Up)

\begin{tabular}{|c|c|c|c|c|}
\hline \multirow[b]{2}{*}{ Outcome: } & \multicolumn{2}{|c|}{ Boys } & \multicolumn{2}{|c|}{ Girls } \\
\hline & $\begin{array}{c}\text { (1) } \\
\text { Lottery Only }\end{array}$ & $\begin{array}{c}\text { (2) } \\
\text { Lottery + Assets }\end{array}$ & $\begin{array}{c}\text { (3) } \\
\text { Lottery Only }\end{array}$ & $\begin{array}{c}\text { (4) } \\
\text { Lottery + Assets }\end{array}$ \\
\hline \multicolumn{5}{|l|}{ Panel A: Outcomes for Ages 7-12 } \\
\hline Worked for wage last month & $\begin{array}{c}-0.005 \\
(0.009) \\
6,205 \\
0.019\end{array}$ & $\begin{array}{c}-0.004 \\
(0.007) \\
6,205 \\
0.019\end{array}$ & $\begin{array}{c}-0.001 \\
(0.007) \\
5,758 \\
0.012\end{array}$ & $\begin{array}{c}-0.002 \\
(0.006) \\
5,758 \\
0.012\end{array}$ \\
\hline Worked 20+ hours for wage last month & $\begin{array}{c}-0.002 \\
(0.005) \\
6,195 \\
0.005\end{array}$ & $\begin{array}{c}-0.001 \\
(0.004) \\
6,195 \\
0.005\end{array}$ & $\begin{array}{c}0.001 \\
(0.004) \\
5,752 \\
0.003\end{array}$ & $\begin{array}{c}0.001 \\
(0.003) \\
5,752 \\
0.003\end{array}$ \\
\hline Panel B: Outcomes for Ages 13-15 & & & & \\
\hline Worked for wage last month & $\begin{array}{c}-0.068 * * \\
(0.029) \\
2,988 \\
0.116\end{array}$ & $\begin{array}{c}-0.044 * \\
(0.026) \\
2,988 \\
0.116\end{array}$ & $\begin{array}{c}-0.012 \\
(0.024) \\
2,769 \\
0.065\end{array}$ & $\begin{array}{c}-0.014 \\
(0.022) \\
2,769 \\
0.065\end{array}$ \\
\hline Worked 20+ hours for wage last month & $\begin{array}{c}-0.044 * \\
(0.024) \\
2,957 \\
0.069\end{array}$ & $\begin{array}{c}-0.030 \\
(0.021) \\
2,957 \\
0.069\end{array}$ & $\begin{array}{c}-0.011 \\
(0.019) \\
2,751 \\
0.039\end{array}$ & $\begin{array}{c}-0.013 \\
(0.018) \\
2,751 \\
0.039\end{array}$ \\
\hline
\end{tabular}

Note: This table disaggregates the 6-year child labor outcomes shown in Table 5 by child's gender. Standard errors, clustered by sub-district, are shown in parentheses.

$* p<0.1 * * p<0.05 * * * p<0.01$. 
Appendix Table 19: IV Effect of PKH on Alternative Child Labor Outcomes

\begin{tabular}{|c|c|c|c|c|}
\hline \multirow[b]{2}{*}{ Outcome: } & \multicolumn{2}{|c|}{ 2-Year } & \multicolumn{2}{|c|}{ 6-Year } \\
\hline & $\begin{array}{c}\text { (1) } \\
\text { Lottery Only }\end{array}$ & $\begin{array}{c}(2) \\
\text { Lottery + Assets }\end{array}$ & $\begin{array}{c}\text { (3) } \\
\text { Lottery Only }\end{array}$ & $\begin{array}{c}(4) \\
\text { Lottery + Assets }\end{array}$ \\
\hline \multicolumn{5}{|l|}{ Panel A: Outcomes for Ages 7-12 } \\
\hline \multirow[t]{4}{*}{ Worked for family business last month } & 0.038 & 0.035 & 0.022 & 0.008 \\
\hline & $(0.030)$ & $(0.026)$ & $(0.029)$ & $(0.026)$ \\
\hline & 11,958 & 11,958 & 11,963 & 11,963 \\
\hline & 0.563 & 0.563 & 0.518 & 0.518 \\
\hline \multirow[t]{4}{*}{ Worked $20+$ hours for family business last month } & 0.005 & 0.005 & -0.013 & -0.009 \\
\hline & $(0.009)$ & $(0.009)$ & $(0.008)$ & $(0.008)$ \\
\hline & 11,897 & 11,897 & 11,900 & 11,900 \\
\hline & 0.021 & 0.021 & 0.024 & 0.024 \\
\hline \multirow[t]{4}{*}{ Helped at home last month } & 0.035 & 0.036 & 0.025 & 0.017 \\
\hline & $(0.031)$ & $(0.028)$ & $(0.029)$ & $(0.026)$ \\
\hline & 11,958 & 11,958 & 11,963 & 11,963 \\
\hline & 0.565 & 0.565 & 0.516 & 0.516 \\
\hline \multirow[t]{4}{*}{ Helped 20+ hours at home last month } & -0.007 & -0.020 & 0.000 & 0.003 \\
\hline & $(0.023)$ & $(0.022)$ & $(0.022)$ & $(0.021)$ \\
\hline & 11,939 & 11,939 & 11,908 & 11,908 \\
\hline & 0.157 & 0.157 & 0.124 & 0.124 \\
\hline \multicolumn{5}{|l|}{ Panel B: Outcomes for Ages 13-15 } \\
\hline \multirow[t]{4}{*}{ Worked for family business last month } & 0.050 & $0.056 * *$ & -0.011 & -0.013 \\
\hline & $(0.033)$ & $(0.028)$ & $(0.034)$ & $(0.029)$ \\
\hline & 5,569 & 5,569 & 5,757 & 5,757 \\
\hline & 0.750 & 0.750 & 0.710 & 0.710 \\
\hline \multirow[t]{4}{*}{ Worked $20+$ hours for family business last month } & $0.040 * *$ & $0.038 *$ & $-0.041^{*} *$ & -0.029 \\
\hline & $(0.020)$ & $(0.023)$ & $(0.019)$ & $(0.020)$ \\
\hline & 5,510 & 5,510 & 5,702 & 5,702 \\
\hline & 0.060 & 0.060 & 0.075 & 0.075 \\
\hline \multirow[t]{4}{*}{ Helped at home last month } & 0.045 & 0.043 & 0.022 & 0.025 \\
\hline & $(0.034)$ & $(0.030)$ & $(0.033)$ & $(0.028)$ \\
\hline & 5,569 & 5,569 & 5,757 & 5,757 \\
\hline & 0.759 & 0.759 & 0.706 & 0.706 \\
\hline \multirow[t]{4}{*}{ Helped 20+ hours at home last month } & -0.038 & -0.011 & -0.017 & 0.006 \\
\hline & $(0.042)$ & $(0.038)$ & $(0.034)$ & $(0.031)$ \\
\hline & 5,552 & 5,552 & 5,733 & 5,733 \\
\hline & 0.327 & 0.327 & 0.265 & 0.265 \\
\hline
\end{tabular}

Note: This table replicates Table 5, but examines the effect of PKH receipt on other measures of child labor. Standard errors, clustered by sub-district, are shown in parentheses.

$* p<0.1 * * p<0.05 * * * p<0.01$. 
Appendix Table 20: Interactions of Child Labor/School Enrollment Outcomes

\begin{tabular}{|c|c|c|c|c|}
\hline \multirow[b]{2}{*}{ Outcome: } & \multicolumn{2}{|c|}{ 2-Year } & \multicolumn{2}{|c|}{ 6-Year } \\
\hline & $\begin{array}{c}\text { (1) } \\
\text { Lottery Only }\end{array}$ & $\begin{array}{c}(2) \\
\text { Lottery + Assets }\end{array}$ & $\begin{array}{c}\text { (3) } \\
\text { Lottery Only }\end{array}$ & $\begin{array}{c}(4) \\
\text { Lottery + Assets }\end{array}$ \\
\hline \multicolumn{5}{|l|}{ Panel A: Outcomes for Ages 7-12 } \\
\hline Enrolled in school $\times$ worked for wage last month & $\begin{array}{c}-0.011 \\
(0.007) \\
11,957 \\
0.019\end{array}$ & $\begin{array}{c}-0.007 \\
(0.007) \\
11,957 \\
0.019\end{array}$ & $\begin{array}{c}-0.006 \\
(0.006) \\
11,963 \\
0.014\end{array}$ & $\begin{array}{c}-0.005 \\
(0.005) \\
11,963 \\
0.014\end{array}$ \\
\hline Enrolled in school $\times$ no work for wage last month & $\begin{array}{c}0.048 * * * \\
(0.012) \\
11,957 \\
0.940\end{array}$ & $\begin{array}{c}0.051 * * * \\
(0.012) \\
11,957 \\
0.940\end{array}$ & $\begin{array}{c}0.018 * \\
(0.010) \\
11,963 \\
0.957\end{array}$ & $\begin{array}{c}0.020 * * \\
(0.009) \\
11,963 \\
0.957\end{array}$ \\
\hline Not enrolled in school $\times$ worked for wage last month & $\begin{array}{c}-0.004 * * \\
(0.002) \\
11,957 \\
0.003\end{array}$ & $\begin{array}{c}-0.003 * \\
(0.002) \\
11,957 \\
0.003\end{array}$ & $\begin{array}{c}0.004 * \\
(0.002) \\
11,963 \\
0.001\end{array}$ & $\begin{array}{c}0.002 \\
(0.002) \\
11,963 \\
0.001\end{array}$ \\
\hline Panel B: Outcomes for Ages 13-15 & & & & \\
\hline Enrolled in school $\times$ worked for wage last month & $\begin{array}{c}-0.006 \\
(0.014) \\
5,568 \\
0.038\end{array}$ & $\begin{array}{c}0.003 \\
(0.013) \\
5,568 \\
0.038\end{array}$ & $\begin{array}{c}-0.025^{*} \\
(0.013) \\
5,757 \\
0.041\end{array}$ & $\begin{array}{c}-0.021 * \\
(0.012) \\
5,757 \\
0.041\end{array}$ \\
\hline Enrolled in school $\times$ no work for wage last month & $\begin{array}{c}0.127 * * * \\
(0.034) \\
5,568 \\
0.745\end{array}$ & $\begin{array}{c}0.123 * * * \\
(0.031) \\
5,568 \\
0.745\end{array}$ & $\begin{array}{c}0.115^{* * * *} \\
(0.029) \\
5,757 \\
0.785\end{array}$ & $\begin{array}{c}0.102 * * * \\
(0.027) \\
5,757 \\
0.785\end{array}$ \\
\hline Not enrolled in school $\times$ worked for wage last month & $\begin{array}{c}-0.035 * * \\
(0.016) \\
5,568 \\
0.059\end{array}$ & $\begin{array}{c}-0.026 * \\
(0.015) \\
5,568 \\
0.059\end{array}$ & $\begin{array}{c}-0.019 \\
(0.016) \\
5,757 \\
0.051\end{array}$ & $\begin{array}{c}-0.010 \\
(0.015) \\
5,757 \\
0.051\end{array}$ \\
\hline
\end{tabular}

Note: This table examines interactions between school enrollment and wage work for the age groups examined in Tables 4 and 5. Baseline controls and fixed effects are as listed in Table 1. Standard errors, clustered by subdistrict, are shown in parentheses.

$* p<0.1 * * p<0.05 * * * p<0.01$. 
Appendix Table 21: IV Effect of PKH on High School Enrollment, by Age

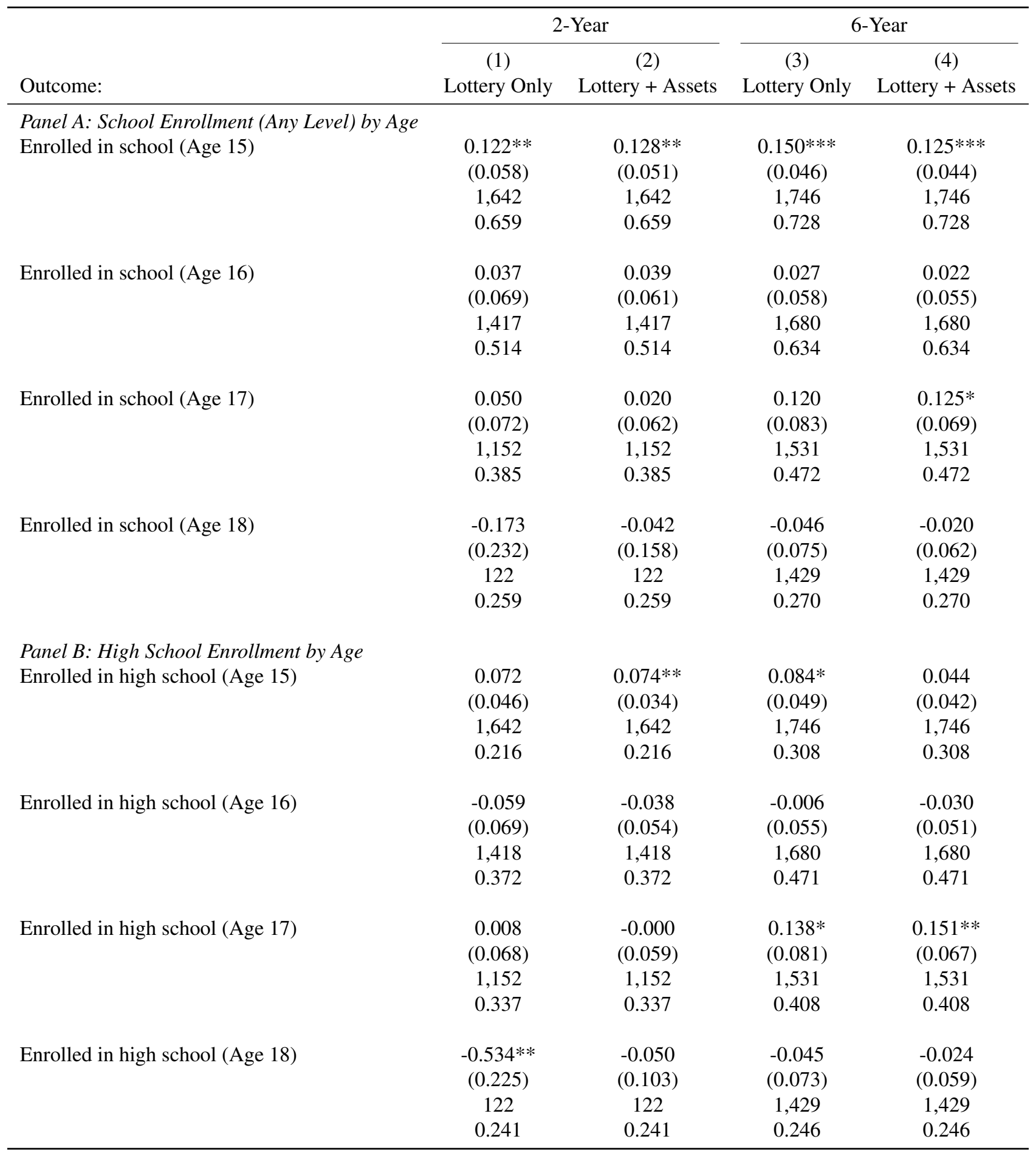

Note: This table explores school enrollment outcomes disaggregated by year of age. Panel A shows school outcomes for enrollment in any level of school; Panel B shows outcomes for high school enrollment only. Standard errors, clustered by sub-district, are shown in parentheses.

$* p<0.1 * * p<0.05 * * * p<0.01$. 
Appendix Table 22: IV Effect of PKH on Medium-Run Outcomes, by Gender (6-Year Follow-Up)

\begin{tabular}{|c|c|c|c|c|}
\hline \multirow[b]{2}{*}{ Outcome: } & \multicolumn{2}{|c|}{ Boys } & \multicolumn{2}{|c|}{ Girls } \\
\hline & $\begin{array}{c}\text { (1) } \\
\text { Lottery Only }\end{array}$ & $\begin{array}{c}(2) \\
\text { Lottery + Assets }\end{array}$ & $\begin{array}{c}\text { (3) } \\
\text { Lottery Only }\end{array}$ & $\begin{array}{c}\text { (4) } \\
\text { Lottery + Assets }\end{array}$ \\
\hline \multicolumn{5}{|l|}{ Panel A: School Enrollment/Completion Outcomes } \\
\hline \multirow[t]{4}{*}{ Enrolled in school (Ages 15-17) } & $0.156 * * *$ & $0.140 * * *$ & 0.057 & 0.047 \\
\hline & $(0.058)$ & $(0.051)$ & $(0.056)$ & $(0.051)$ \\
\hline & 2,616 & 2,616 & 2,341 & 2,341 \\
\hline & 0.589 & 0.589 & 0.646 & 0.646 \\
\hline \multirow[t]{4}{*}{ Enrolled in high school (Ages 15-17) } & $0.132 * * *$ & $0.092 * *$ & 0.001 & 0.012 \\
\hline & $(0.049)$ & $(0.044)$ & $(0.056)$ & $(0.049)$ \\
\hline & 2,616 & 2,616 & 2,341 & 2,341 \\
\hline & 0.345 & 0.345 & 0.447 & 0.447 \\
\hline \multirow[t]{4}{*}{ Completed high school (Ages 18-21) } & $0.097 * *$ & 0.049 & 0.037 & 0.005 \\
\hline & $(0.046)$ & $(0.038)$ & $(0.065)$ & $(0.053)$ \\
\hline & 2,345 & 2,345 & 1,918 & 1,918 \\
\hline & 0.232 & 0.232 & 0.292 & 0.292 \\
\hline \multicolumn{5}{|l|}{ Panel B: Labor Outcomes (Ages 16-21) } \\
\hline \multirow[t]{4}{*}{ Worked for wage last month (Ages 16-17) } & 0.050 & 0.049 & -0.008 & 0.000 \\
\hline & $(0.057)$ & $(0.053)$ & $(0.050)$ & $(0.044)$ \\
\hline & 1,697 & 1,697 & 1,514 & 1,514 \\
\hline & 0.276 & 0.276 & 0.160 & 0.160 \\
\hline \multirow[t]{4}{*}{ Worked 20+ hours for wage last month (Ages 16-17) } & -0.011 & -0.020 & 0.004 & -0.007 \\
\hline & $(0.053)$ & $(0.051)$ & $(0.047)$ & $(0.040)$ \\
\hline & 1,652 & 1,652 & 1,500 & 1,500 \\
\hline & 0.214 & 0.214 & 0.127 & 0.127 \\
\hline \multirow[t]{4}{*}{ Worked for wage last month (Ages 18-21) } & -0.009 & 0.003 & -0.105 & -0.066 \\
\hline & $(0.056)$ & $(0.047)$ & $(0.074)$ & $(0.057)$ \\
\hline & 2,345 & 2,345 & 1,918 & 1,918 \\
\hline & 0.584 & 0.584 & 0.344 & 0.344 \\
\hline \multirow[t]{4}{*}{ Worked 20+ hours for wage last month (Ages 18-21) } & 0.013 & 0.028 & -0.092 & -0.063 \\
\hline & $(0.057)$ & $(0.049)$ & $(0.072)$ & $(0.055)$ \\
\hline & 2,260 & 2,260 & 1,879 & 1,879 \\
\hline & 0.514 & 0.514 & 0.311 & 0.311 \\
\hline \multicolumn{5}{|l|}{ Panel C: Marriage Outcomes (Ages 16-21) } \\
\hline \multirow[t]{4}{*}{ Married (Ages 16-17) } & -0.005 & -0.006 & -0.001 & 0.002 \\
\hline & $(0.007)$ & $(0.005)$ & $(0.049)$ & $(0.043)$ \\
\hline & 1,594 & 1,594 & 1,438 & 1,438 \\
\hline & 0.004 & 0.004 & 0.112 & 0.112 \\
\hline \multirow[t]{4}{*}{ Married (Ages 18-21) } & -0.028 & -0.018 & -0.024 & -0.024 \\
\hline & $(0.021)$ & $(0.021)$ & $(0.068)$ & $(0.056)$ \\
\hline & 2,259 & 2,259 & 1,864 & 1,864 \\
\hline & 0.047 & 0.047 & 0.360 & 0.360 \\
\hline
\end{tabular}

Note: This table explores the 6-year schooling, labor, and marriage outcomes presented in Table 6, disaggregated by child's gender. Standard errors, clustered by sub-district, are shown in parentheses.

$* p<0.1 * * p<0.05 * * * p<0.01$. 
Appendix Table 23: IV Effect of PKH on Alternative Work Outcomes, by Gender (6-Year Follow-Up)

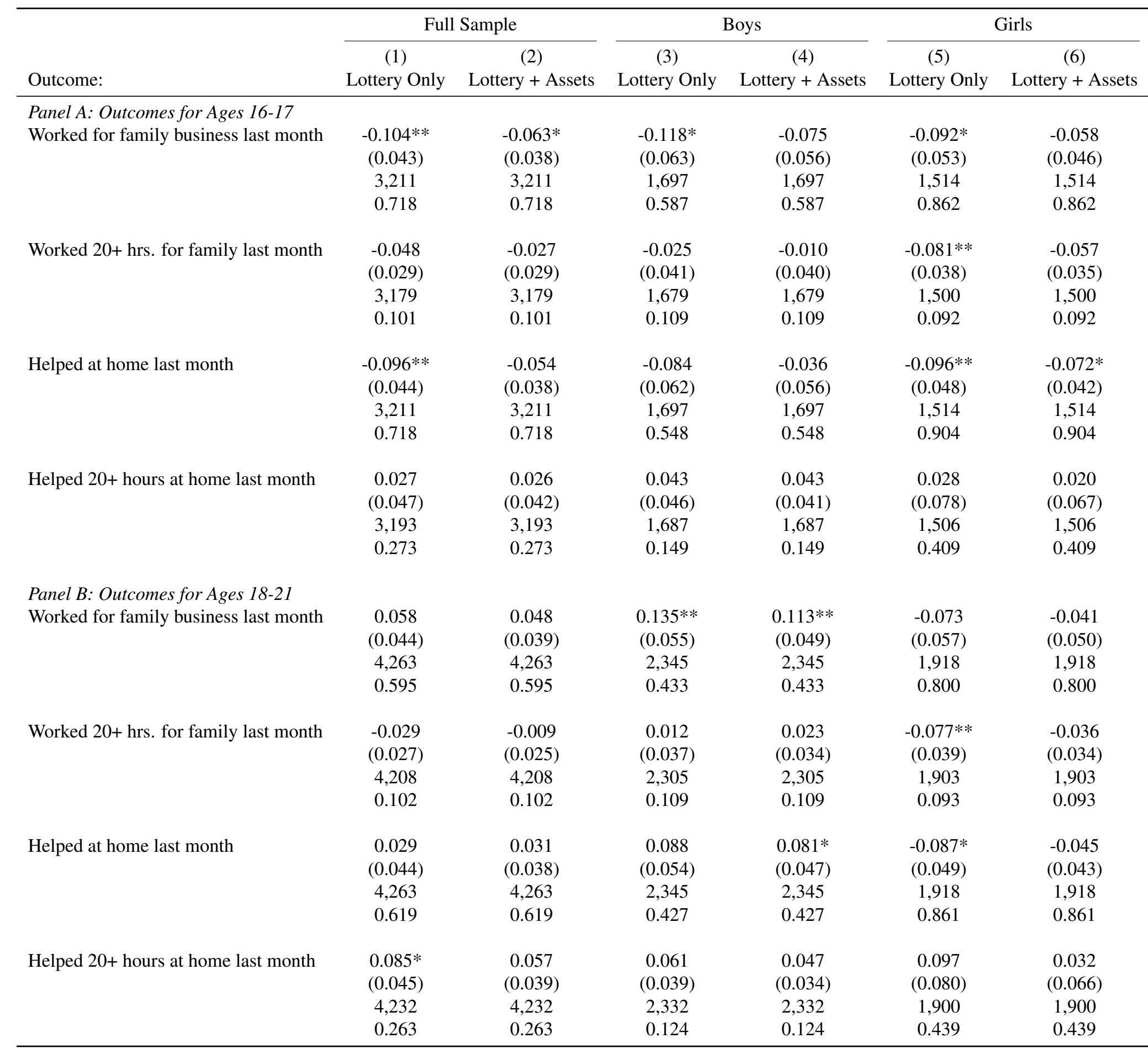

Note: This table explores alternative 6-year labor outcomes for the same age groups (16-17 and 18-21 years) presented in Table 6 and Appendix Table 19. Standard errors, clustered by sub-district, are shown in parentheses.

$* p<0.1 * * p<0.05 * * * p<0.01$. 
Appendix Table 24: IV Effect of PKH on Fertility Outcomes

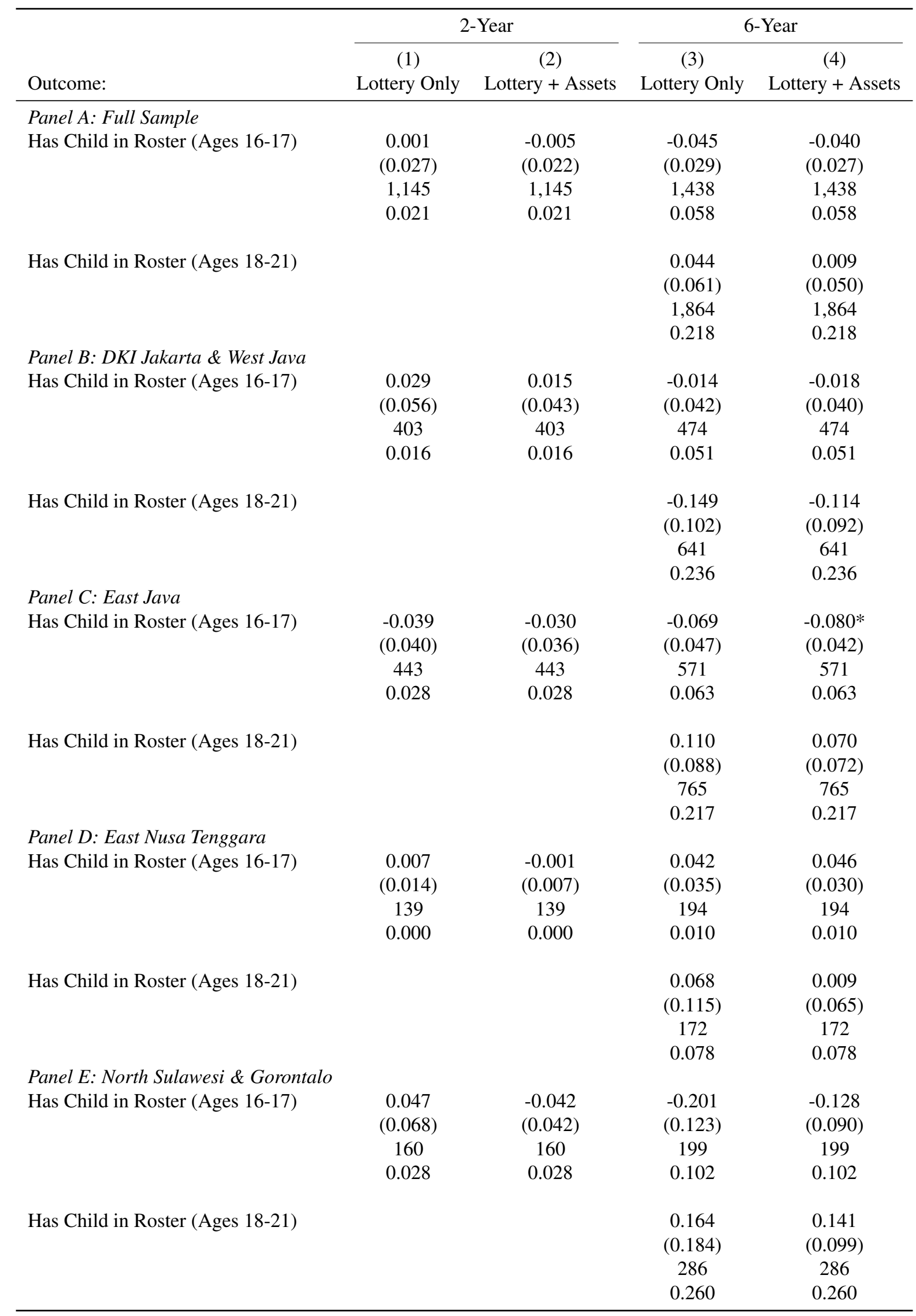

Note: This table examines fertility rates among girls who were in our sample at baseline. Fertility status is determined by whether baseline respondents have children listed in the household roster in each follow-up survey. In Panel A, we examine outcomes for the entire sample, irrespective of province. In Panels B through E, we disaggregate these results by province. Baseline controls and fixed effects are as listed in Table 1. Standard errors, clustered by sub-district, are shown in parentheses.

$* p<0.1 * * p<0.05 * * * p<0.01$. 
Appendix Table 25: IV Effect of PKH on Household Per-Capita Expenditure, by Province

\begin{tabular}{|c|c|c|c|c|}
\hline \multirow[b]{3}{*}{ Outcome: } & \multicolumn{2}{|c|}{ 2-Year } & \multicolumn{2}{|c|}{ 6-Year } \\
\hline & (1) & (2) & (3) & (4) \\
\hline & Lottery Only & Lottery + Assets & Lottery Only & Lottery + Assets \\
\hline \multirow[t]{4}{*}{ Log per-capita expenditure (DKI Jakarta \& West Java) } & -0.019 & 0.007 & -0.045 & -0.034 \\
\hline & $(0.068)$ & $(0.058)$ & $(0.073)$ & $(0.059)$ \\
\hline & 3,453 & 3,453 & 3,746 & 3,746 \\
\hline & 12.374 & 12.374 & 12.912 & 12.912 \\
\hline \multirow[t]{4}{*}{ Log per-capita expenditure (East Java) } & -0.001 & 0.009 & 0.052 & 0.045 \\
\hline & $(0.043)$ & $(0.040)$ & $(0.044)$ & $(0.040)$ \\
\hline & 7,084 & 7,084 & 7,444 & 7,444 \\
\hline & 12.344 & 12.344 & 12.929 & 12.929 \\
\hline \multirow[t]{4}{*}{ Log per-capita expenditure (East Nusa Tenggara) } & -0.001 & 0.007 & $0.105^{*}$ & 0.074 \\
\hline & $(0.055)$ & $(0.055)$ & $(0.056)$ & $(0.050)$ \\
\hline & 2,115 & 2,115 & 2,230 & 2,230 \\
\hline & 12.246 & 12.246 & 12.622 & 12.622 \\
\hline \multirow[t]{4}{*}{ Log per-capita expenditure (North Sulawesi \& Gorontalo) } & -0.088 & -0.106 & 0.057 & 0.023 \\
\hline & $(0.154)$ & $(0.089)$ & $(0.164)$ & $(0.097)$ \\
\hline & 1,948 & 1,948 & 2,079 & 2,079 \\
\hline & 12.467 & 12.467 & 13.050 & 13.050 \\
\hline
\end{tabular}

Note: This table shows log per-capita expenditure outcomes disaggregated by province. Due to the small number of households from DKI Jakarta and Gorontalo represented in our sample, we group these provinces with geographically adjacent provinces (West Java and North Sulawesi, respectively) in the regressions shown above. Baseline controls and fixed effects are as listed in Table 1. Standard errors, clustered by sub-district, are shown in parentheses.

$* p<0.1 * * p<0.05 * * * p<0.01$. 